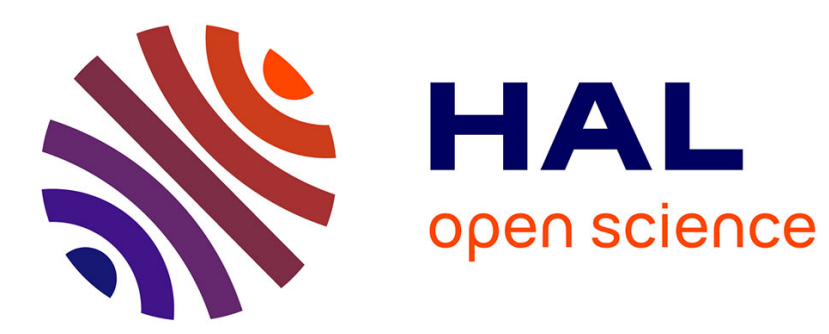

\title{
Natural Catastrophe Insurance: When Should the Government Intervene?
}

Arthur Charpentier, Benoît Le Maux

\section{To cite this version:}

Arthur Charpentier, Benoît Le Maux. Natural Catastrophe Insurance: When Should the Government Intervene?. Journal of Public Economics, 2014, epub ahead of print. 10.1016/j.jpubeco.2014.03.004 . hal-00536925v1

\section{HAL Id: hal-00536925 https://hal.science/hal-00536925v1}

Submitted on 17 Nov 2010 (v1), last revised 23 Jan 2015 (v2)

HAL is a multi-disciplinary open access archive for the deposit and dissemination of scientific research documents, whether they are published or not. The documents may come from teaching and research institutions in France or abroad, or from public or private research centers.
L'archive ouverte pluridisciplinaire HAL, est destinée au dépôt et à la diffusion de documents scientifiques de niveau recherche, publiés ou non, émanant des établissements d'enseignement et de recherche français ou étrangers, des laboratoires publics ou privés. 


\title{
ECOLE POLYTECHNIQUE
}

\section{Natural Catastrophe Insurance: When Should the Government Intervene?}

\author{
Arthur CHARPENTIER \\ Benoît LE MAUX
}

Cahier $^{\circ} \quad 2010-26$

\section{DEPARTEMENT D'ECONOMIE \\ Route de Saclay \\ 91128 PALAISEAU CEDEX \\ (33) 169333033 \\ http://www.economie.polytechnique.edu/ \\ mailto:chantal.poujouly@polytechnique.edu}




\title{
Natural Catastrophe Insurance: When Should the Government Intervene?
}

\author{
Arthur CHARPENTIER* \\ arthur.charpentier@univ-rennes1.fr \\ University of Rennes 1, CREM-CNRS, Ecole Polytechnique \\ Benoît LE MAUX ${ }^{\dagger}$ \\ benoit.le-maux@univ-rennes1.fr \\ University of Rennes 1, CREM-CNRS \\ Preliminary draft. Please do not quote \\ (Comments are welcome)
}

Tuesday $9^{\text {th }}$ November, 2010

\begin{abstract}
The present research relaxes three of the usual assumptions made in the insurance literature. It is assumed that (1) there is a finite number of risks, (2) the risks are not statistically independent and (3) the structure of the market is monopolistic. In this context, the article analyses two models of natural catastrophe insurance: a model of insurance with limited liability and a model with unlimited guarantee. Among others, the results confirm the idea that the natural catastrophe insurance industry is characterized by economies of scale. The government should consequently encourage the emergence of a monopoly and discipline the industry through regulated premiums. It is also shown that government intervention of last resort is not needed when the risks are highly correlated. Lastly, the results point out that when the risks between two regions are not sufficiently independent, the pooling of the risks can lead to a Pareto improvement only if the regions face similar magnitude of damage. If not, then the region with low-damage events needs the premium to decrease to accept the pooling of the risks.
\end{abstract}

JEL-Classification: G22, G28

Keywords: Insurance, Ruin, Natural Catastrophe, Market Failure, Government Intervention

${ }^{*}$ This work has been partially supported by the French Research National Agency (ANR) under the reference ANR-08-BLAN-0314-01, and financial support from the AXA Chair on Large Risks in Insurance (Fondation du Risque).

${ }^{\dagger}$ Corresponding author: Benoît Le Maux, University of Rennes 1, 7 Place Hoche, 35065 Rennes Cedex, France. E-mail: benoit.le-maux@univ-rennes1.fr. Tel: + 332232335 67. Fax: + 33223233599. 


\section{Introduction}

In this paper, we try to understand insurance demand and supply decision-making when ruin is endogenous. In the pioneer models of insurance demand, several factors are assumed to play a significant role in the determination of insurance market equilibriums, including individual wealth, the probability of loss, the insurance premium, the contract, and the utility function of the individual (Borch, 1960; Smith, 1968; Mossin, 1968; Gould, 1969). In addition, the assumption is made that both individuals and insurers are able to form accurate estimates of the probabilities associated with all possible loss outcomes. In that case, the models predict that full coverage insurance will be purchased if insurance is offered at a fair price. At unfair prices, individuals will purchase only partial coverage insurance (Mossin 1968, Smith, 1968). Following this literature, standard theories of adverse selection, dating from Akerlof (1970) and Rothschild and Stiglitz (1976), have analyzed the impact of imperfect information on insurance market equilibriums. The usual assumption is that the insurer cannot distinguish between low-risk and high-risk individuals. As a result, if insurance is available at the same price to all customers, individuals with the greatest risks are more likely to buy insurance than low-risk individuals.

Of course, the applicability of the adverse selection literature is considerable (examples of adverse selection include second-hand car market, labor market, credit card market), and this literature has found support in many empirical studies (see for instance Wang et al., 2009 for an updated survey about insurance market). However, several authors recognize that adverse selection theories may not be suited to the analysis of natural catastrophe insurance. The reason is that information asymmetry could be all the way around (Kunreuther, 1984). People could either overestimate or underestimate their true probability of loss (Smith and Desvouges, 1987; Kunreuther et al.,1988; McClelland et al., 1990; and McClelland et al., 1993), while insurance companies have better access to information using predicting and riskspreading techniques to rate the catastrophe exposures.

Another important issue in the analysis of natural catastrophe insurance is the fact that natural risks are not statistically independent and diversification through the central limit theorem is not easily reached because of geographical correlation (a lot of additional capital is required), which increases the chances of financial ruin (Charpentier, 2007). As a result, natural catastrophe insurance policies are not always performing contracts, because valid insurance claims are not always fully paid by the insurers in case of bankrupt. To our knowledge, only a few papers directly consider the effects of default risk on the demand and supply for insurance (see Tapiero et al., 1986; Doherty and Garven, 1986; Schlesinger and Schuleburg, 1987; Johnson and Stulz, 1987 and Doherty and Schlesinger, 1990). The main idea of these models is to incorporate a default risk into the insurance-pricing decision and the expected utility of purchasers. For example, Doherty and Schlesinger (1990) assume that the insurer will be solvent or insolvent with some probability, conditional on the occurrence of a loss. Unfortunately, this solvency probability is assumed to be exogenous in the model and does not take into account the fact that risks could be correlated in the economy. Our article tries to fill in this gap by focusing on recent developments in ruin theory and nonindependence modeling. 
The present research relaxes three of the usual assumptions made in the insurance literature. It will be assumed that (1) there is a finite number of risks, (2) the risks are not statistically independent and (3) the structure of the market is monopolistic. The article first analyses two models of natural catastrophe insurance: a model of insurance with limited liability (i.e., without government intervention) and a model with unlimited guarantee (i.e., the government intervenes as an insurer of last resort). The models are then investigated by simulations method using a probabilistic mixture model made of two binomial distributions. Lastly, the article extends the models by focusing on a simultaneous non-cooperative game combining two regions with heterogeneous natural risks. Among others, the results confirm the idea that the natural catastrophe insurance industry is characterized by economies of scale. The government should consequently encourage the emergence of a monopoly and discipline the industry through regulated premiums. It is also shown that government intervention of last resort is not needed when the risks are highly correlated. Lastly, the results point out that when the risks between two regions are not sufficiently independent, the pooling of the risks can lead to a Pareto improvement only if the regions face similar magnitude of damage. If not, then the region with low-damage events needs the premium to decrease to accept the pooling of the risks.

The outline of the article is as follows. Section 2 develops the two models of natural catastrophe insurance with and without government intervention. Section 3 presents the simulations and compares the models' equilibriums. Section 4 discusses the role of the government in the natural catastrophe insurance industry. Section 5 extends the model to a two-region economy. Section 6 provides the conclusion.

\section{Two models of natural catastrophe insurance}

Consider an economy with $n$ inhabitants. This economy is exposed to natural events which can cause a loss $l$ to $N$ of its citizens. The stochastic process $X$, with $X=\frac{N}{n} \in[0 ; 1]$, describes the set of possible states of nature according to the share of the population claiming a loss. More specifically, the natural events are based on the following increasing continuous probability distribution:

$$
F=F(x \mid p, \delta)=F(x) \in[0 ; 1]
$$

with:

$$
\frac{\partial F}{\partial p}<0 \forall x \in[0 ; 1], \frac{\partial F}{\partial \delta}<0 \forall x>x^{*}, \frac{\partial^{2} F}{\partial \delta^{2}}>0 \forall x>x^{*}, \frac{\partial^{2} F}{\partial p^{2}}>0 \forall x>x^{*},
$$

for some $x^{*}$, where $p$ represents the probability for an individual to claim a loss and $\delta$ stands for the correlation between the individual risks. The above assumptions may be interpreted as follows. First, the higher the probability $p$ to claim a loss, the lower the chances for $X$ to be less than $x$ or similarly the higher the chances to be greater than $x$. Second, for high values of $x$, greater than $x^{*}$, it is assumed that the correlation between the risks increases the probability for $X$ to be greater than $x$. In other words, the probability that there is a high number of people 
Table 1. Comparison of final losses $Y$ in case of ruin.

\begin{tabular}{lc|c|c|c}
\hline \hline & \multicolumn{2}{c}{$\begin{array}{c}\text { Individual claiming no loss } \\
\text { (with a probability } 1-p \text { ) }\end{array}$} & \multicolumn{2}{c}{$\begin{array}{c}\text { Individual claiming a loss } \\
\text { (with a probability } p \text { ) }\end{array}$} \\
\hline & Insurance & No insurance & Insurance & No Insurance \\
\hline Without intervention & $-\alpha$ & 0 & $-\alpha-l+I(X)$ & $-l$ \\
With intervention & $-\alpha-T(X)$ & 0 & $-\alpha-T(X)$ & $-l$ \\
Infinite number of independent risks & $-\alpha$ & 0 & $-\alpha$ & $-l$ \\
\hline \hline
\end{tabular}

claiming a loss increases with $\delta$. In addition, this probability is assumed to increase at an increasing marginal rate with both $\delta$ and $p$. Subsection 3.2 provides an example of such a probability distribution.

\subsection{Model without government intervention}

In this subsection, insurance coverage is provided by a single private company with limited liability. Following Einav et al. (2010), we take the characteristics of the insurance contracts as given: only the pricing of the contracts are determined endogenously, not the offered coverage. More specifically, the inhabitants of the economy have to decide simultaneously whether or not to pay full insurance coverage. The value of the premium they would have to pay is denoted by $\alpha$. The economic capital per policy held by the company is denoted by $c$. The company can go bankrupt if it is not possible anymore to pay the full coverage $l$ to the victims, i.e., if the total losses $(\mathrm{Nl})$ are higher than the company's turnover $(n \alpha)$ plus the total economic capital $(n c)$. Consequently, the probability of bankrupt is:

$$
\mathbb{P}(\text { Ruin })=\mathbb{P}(N l>n \alpha+n c)=\mathbb{P}\left(\frac{N}{n}>\frac{\alpha+c}{l}\right)=\mathbb{P}\left(X>\frac{\alpha+c}{l}\right)=1-F(\bar{x}),
$$

where $\bar{x}=(\alpha+c) / l$ denotes the maximum share of insured people claiming a loss without bankrupt. The higher the premium and the capital per head, the higher $\bar{x}$ and the lower the ruin probability.

For simplicity of exposition, the inhabitants are assumed to be identical with same wealth $w$ and same risk aversion. ${ }^{1}$ Following Rothschild and Stiglitz (1976), they are assumed to maximize their expected utility which depends on preference $u=u(w+Y)$ where $Y$ is a negative random loss with $-Y \leq w$. In other words, the final wealth of the agents remains always positive, the limiting case being $w+Y=0$, i.e., they lose everything. As such, risk aversion of agents is consistent with standard prospect theory results (Kahneman and Tversky, 1979). Since the inhabitants have identical wealth, the focus can be on a simplified utility function $U=U(Y)$, with $U(0)=0$. The function $U$ is assumed to be twice differentiable, increasing and stricly concave, i.e., inhabitants are risk-averse. The final payoff $Y$ are

\footnotetext{
${ }^{1}$ Although this case will not be examined in the present paper, it should be stressed that the two-region model presented in Section 5 allows to take into account different risk aversions, simply by assuming identical withinand between-correlations but different forms of utility function.
} 
presented in the first row of Table 1. They are determined by both the eventuality of a loss and the decision to buy insurance. If an individual does not claim a loss, the payoff is $(-\alpha)$ with insurance, and 0 without insurance. If the individual is claiming, the payoff is $(-\alpha-l+I)$ with insurance and $(-l)$ without, where $I$ represents the indemnity. If the insurance company does not go bankrupt, this indemnity is fully covers the loss $l$. In case of bankrupt, the indemnity received by each insured victim is equal to the total economic capital $(n c)$ plus the company's turnover $(n \alpha)$, divided by the number of insured claiming a loss:

$$
I(X)=\frac{n(c+\alpha)}{N}=\frac{c+\alpha}{X} \geq 0
$$

Since the inhabitants are identical, they will all make the same decision. The purpose of an individual is to decide to purchase or not insurance so as to maximize expected utility. Without insurance, the expected utility depends only on the probability $p$ of a loss:

$$
p U(-l)+(1-p) U(0)=p U(-l) .
$$

On the other hand, with insurance, individuals face a compound lottery where two kinds of risk have to be taken into account. First, the risk to confront a loss with a probability $p$ and, second, the risk that the company goes bankrupt with a probability $1-F(\bar{x})$. In other words, with insurance, the expected utility can be described as follows:

$$
\begin{aligned}
V= & p \mathbb{E}[U(Y) \mid \text { No Ruin }]+p \mathbb{E}[U(Y) \mid \text { Ruin }] \\
& +(1-p) \mathbb{E}[U(Y)] .
\end{aligned}
$$

More specifically, we have:

$$
\begin{aligned}
V(\alpha, p, \delta, c)= & p F(\bar{x}) U(-\alpha)+p \int_{\bar{x}}^{1} U(-\alpha-l+I(x)) f(x) d x \\
& +(1-p) U(-\alpha)
\end{aligned}
$$

which can be written as:

$$
V(\alpha, p, \delta, c)=U(-\alpha)-p \int_{\bar{x}}^{1}[U(-\alpha)-U(-\alpha-l+I(x))] f(x) d x
$$

Hence, the agent will buy insurance if and only if:

$$
V(\alpha, p, \delta, c) \geq p U(-l)
$$

In other words, the decision to insure or not depends on the premium level $(\alpha)$, the loss probability $(p)$, the correlation between the risks $(\delta)$, and the economic capital per head of the firm $(c)$. Notice that Equation 7 is very similar to the expected utility in Doherty and Schlesinger 1990, except that the ruin probability is not exogenous anymore in our model.

Remind that in the usual insurance literature, it assumed that there is an infinite number of risks and that the risks are independent (see for instance Rothschild and Stiglitz (1976)). In our settings, this corresponds to the situation where the ruin probability $1-F(\bar{x})$ is null 


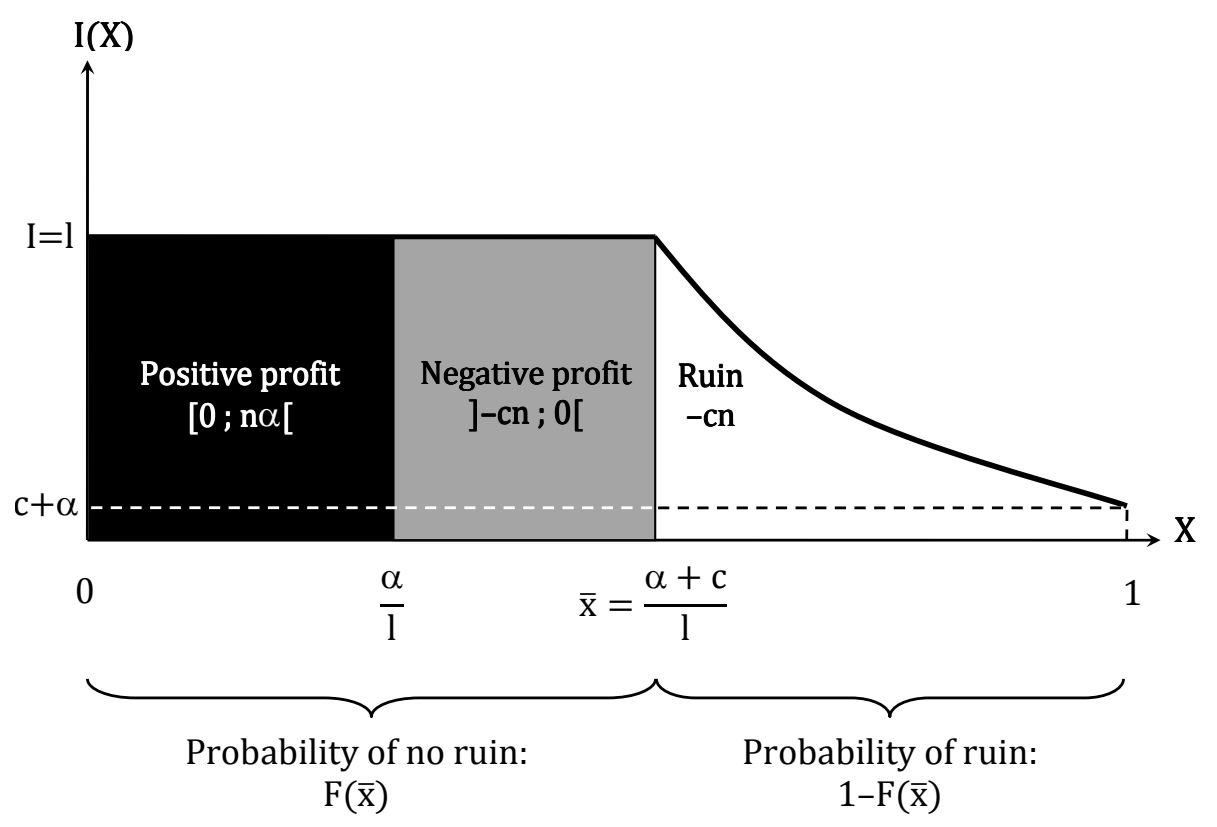

Figure 1. Indemnity and profit of the private company.

and where $I(x)$ always covers the loss $l$. In that case, an insured agent will always reach a utility level equal to $U(-\alpha)$ (see the third row of Table 1 for a comparison of the payoffs). Consequently, the main difference with the existing models of insurance is the presence of $p \int_{\bar{x}}^{1}[U(-\alpha)-U(-\alpha-l+I(x))] f(x) d x$ in Equation 8. Since this term is positive, we already have the result that an increased ruin probability is detrimental to our agents.

The company is assumed to be a risk-neutral private company which chooses the premium $\alpha$ so as to maximize its expected profit. If all the inhabitants decide not to purchase insurance, the profit of the company is zero. If the inhabitants decide to buy insurance, the profit of the insurance company is equal to the company's turnover $(\alpha l)$ minus the total losses claimed by the insured $(\mathrm{Nl})$. Figure 1 provides an illustration of the problem. Depending on the share of population claiming a loss, the profit of the insurance company can be positive or negative, with a minimum equal to $-c n$. More specifically, in case of no bankrupt, the profit of the company is equal to the company turnover minus the indemnities $(l)$ claimed by the victims. In that case, the profit can be positive or negative depending on the amount of losses. On the other hand, in case of bankrupt, the profit is always equal to - cn since the company equally distribute the capital to the insured victims. Consequently, if all the inhabitants decide to purchase insurance, the expected profit of the insurance company is the following:

$$
\Pi(\alpha, p, \delta, c)=\int_{0}^{\bar{x}}[n \alpha-x n l] f(x) d x-[1-F(\bar{x})] c n
$$

The insurance company will provide insurance only if the expected profit is greater than zero. 


\subsection{Model with government intervention}

In the previous subsection, we have considered the case of a private insurance company with limited liability. The model can be quite different when the government intervenes as an insurer of last resort. In that case, we may suppose that full coverage is guarantee in case of ruin. The government will ask for an additional premium (e.g., an increase in premiums or taxes the next years) to all the insured if the losses are higher than the total premium and solvency capital. More specifically, an insured individual will always have a loss equal to $(-\alpha-T)$, where $T$ is a tax and/or additional premium collected by the government when $N l>(\alpha+c) n$, i.e., when $X>\bar{x}$ :

$$
T(X)=\frac{N l-(\alpha+c) n}{n}=X l-\alpha-c \geq 0
$$

Tax calculation is assumed here to be determined solely by the idea of covering the damage costs in case of bankrupt. The difference with the previous model comes from the fact that without government intervention, the citizens still have a chance to pay only $\alpha$ if they do not claim a loss. Here, in contrast, the citizens always have to pay additional taxes/premiums in case of ruin. The expected utility of an individual becomes:

$$
V(\alpha, p, \delta, c)=F(\bar{x}) \times U(-\alpha)+\int_{\bar{x}}^{1} U(-\alpha-T(x)) f(x) d x,
$$

which can be written as:

$$
V(\alpha, p, \delta, c)=U(-\alpha)-\int_{\bar{x}}^{1}[U(-\alpha)-U(-\alpha-T(x))] f(x) d x
$$

Since $T$ is greater than zero, the utility received with government intervention is always less or equal to the utility $U(-\alpha)$ received when there is an infinite number of dependent risks (see Table 1 for a comparison between the losses). In terms of expected utilities, this implies that $V$ is necessarily lower than $U(-\alpha)$ for any value of $\alpha$.

As previously, the agent will buy insurance if and only if $V(\alpha) \geq p U(-l)$. The private company still will be a risk-neutral agent which chooses the premium $\alpha$ so as to maximize its expected profit. If the inhabitants decide not to buy insurance, the profit of the company is zero. If the inhabitants decide to insure, the profit of the insurance company is given by Equation 10. Consequently, the main difference between this model and the model without intervention is that the expected utility $V$ differs when they decide to insure (see Equations 8 and 13).

Notice that this model with unlimited guarantee is directly inspired from the French CatNat system. In France, 'Property insurance'(for people living in rented premises), 'Damage to motor vehicle' and 'Casualty' insurance contracts are compulsory. In that case, any insurance company in the private sector has the obligation to extend the scope of these contracts to include the risk of terrorist attacks, industrial disasters and natural catastrophe (including floods, draughts, earthquakes, and hurricanes). However, homeowner insurance is not compulsory and recent catastrophes revealed that approximately up to $15 \%$ of victims of major disasters do not carry such insurance (Moréteau, 2007). To guarantee their solvency, 
the French private insurance companies can cover for themselves from the reinsurer of their choice. In addition, the insurance companies have the alternative of being reinsured against natural catastrophes by a public-policy institution, the Caisse Centrale de Réassurance (hereafter CCR). The latter enjoys very strong support from the government which provides it with a non-limited guarantee. The CCR consequently obtains good financial-strength ratings, for example (AAA) at Standard and Poor's, and is ranked among the top twenty-five reinsurers in the world.

More specifically, the French system of compensation of victims of catastrophe is funded by additional insurance premiums and, in last resort, by the taxpayers. The rates of additional premium are set by the government, in the form of a decree. From 1983 to 1999, the additional premium represented 5\% of premium or contribution with respect to Property \& Casualty policies. Since 1999 , it represents $12 \%$ of premiums (CCR, 2007). ${ }^{2}$ Half the additional premiums goes to the CCR and the CCR will always cover at least half the damage insured and pay for it. If it is not possible for the CCR to pay for all the damages insured, the CCR has to call for the guarantee of the government. In that case, the government will use the public budget to refund the CCR. It happened only once in year 2000 for a total amount of 3 billion Francs (457 million Euros), because of severe flooding in the South, and the two storms of December 1999. The system works actually similarly to stop-loss reinsurance, where the cedant is the CCR and the reinsurer the French government. More specifically, the French government will intervene if the damages exceeds more than 90\% of the CCR's premium income and reserves for natural catastrophe (see also Magnan, 1995).

Similar systems with unlimited government guarantee may be found in other European countries (e.g., Spain, Switzerland). Insurance for natural catastrophes can also be optional and available only from private insurers for an additional premium (e.g., Germany, Italy, United Kingdom). A survey about the different natural catastrophe insurance systems can be found in von Ungern-Sternberg (2004) and US Government Accountability Office (2005).

\section{Model equilibriums and simulations}

This section first describes the models' equilibrium and provides the main theoretical results we can obtain without assuming any specific form for the probability distribution function $F$ and the utility function $U$ (Subsection 3.1). The next subsection presents a technique used to model dependency between risks and specifies a possible form for the function $F$ in a discrete context (Subsection 3.2). Last subsection investigates the two models of insurance by simulation methods and compares the equilibriums (Subsection 3.3).

\footnotetext{
${ }^{2}$ Notice that there is no reinsurer in the theoretical model, i.e., it is as if the cedant insurer and the reinsurer were the same entity. Moreover, in the model, the premium $\alpha$ is directly chosen by the private company, which is not the case in practice. However, we might think that the premiums are set by the French government so as to maximize the CCR's solvency (i.e., highest possible premiums) subject to the electoral constraint that people do not complain about the premiums. Subsection 3.3 will also consider the possibility that the government aims to maximize social welfare instead of the insurance industry's profit.
} 


\subsection{Definition of equilibriums and main theoretical results}

When the risks are uncorrelated, the economic capital per policy required by an insurance company approaches zero as the number of insured risks approaches infinity. This result implies that insurance companies are more competitive and propose lower premiums as their number of risks increases. Because of these decreasing returns to scale, insurance industry can be said to be a natural monopoly (Emons, 2001) or at least, can be characterized as having an oligopolistic market structure (Cummins and Zi, 1998; Sonnenholzner and Wambach, 2004; Chiappori et al., 2006). This is all the more true when the losses are correlated. In that case, some amount of capital per policy is indeed required even if the number of risks approaches infinity (Cummins, 2006; Jafee, 2006). Moreover, it should be stressed that insurance company solvency is a critical issue with respect to natural disasters. As a result, the insurance industry advocates high levels of premium for many reasons. For instance, (1) high premiums allows for protecting of people and businesses from financial ruin, (2) pre-funding of disasters is better than post-funding, (3) when assessing the risk of a disaster is difficult for a particular area, it is only rational for the industry to assume high disaster risk and charge high premiums. In our model, it can actually be shown that maximizing the expected profit is equivalent to minimizing the ruin probability. Those are the reasons why we decided to concentrate on a model of general equilibrium with monopolistic behavior, by opposition to Rothschild and Stiglitz (1976) for instance who focus on a competitive market. The equilibrium is therefore determined by Equations 9 and 10, with inhabitants maximizing their expected utility and an insurance company maximizing its expected profit. The equilibrium premium will be denoted by $\alpha^{*}$ in both models.

Proposition 1. The expected profit of the insurance company is an increasing function of the premium. As a result, maximizing the expected profit is equivalent to minimizing the ruin probability.

Proof. See Appendix.

With an infinite number of independent risks, i.e., with a zero probability of ruin, an insured agent will always reach a utility level equal to $U(-\alpha)$. In contrast, in our two models, an insured agent will reach a utility below this level. As a result, the premium an agent is willing to pay is lower when ruin is possible. Therefore, the following proposition can be proven:

Proposition 2. When the market has a monopolistic structure, a finite number of dependent risks implies lower equilibrium premiums than an infinite number of independent risks.

Proof. See Appendix.

To understand Proposition 2, recall that the agents will purchase insurance if and only if the premium is such that they can reach a utility level greater than $p U(-l)$ (from Equation 9). But the expected utilities $V$ defined by Equations 8 and 13 are always less than $U(-\alpha)$. Consequently, to make the agents purchase insurance, the premiums in our two models of natural catastrophe insurance necessarily have to be lower than in the case with an infinite 
number of independent risks. This proposition can be extended to the case where only a finite number of risks is involved, although the proof is slightly different:

Proposition 3. The two models of natural catastrophe insurance lead to the following comparative static derivatives:

$$
\begin{array}{llll}
\frac{\partial V}{\partial \delta}<0 & \text { and } & \frac{\partial \alpha^{*}}{\partial \delta}<0, \text { for } \bar{x}>x^{*} \\
\frac{\partial V}{\partial p}<0 & \text { and } & \frac{\partial \alpha^{*}}{\partial p}=?, \text { for } \bar{x}>x^{*} \\
\frac{\partial V}{\partial c}>0 & \text { and } & \frac{\partial \alpha^{*}}{\partial c}>0, \text { for } \bar{x} \in[0 ; 1], \\
\frac{\partial \Pi}{\partial c}<0 & \text { and } & \frac{\partial \Pi}{\partial \alpha^{*}}>0, \text { for } \bar{x} \in[0 ; 1] .
\end{array}
$$

Proof. See Appendix.

Proposition 3 points out the importance of the correlation parameter $\delta$. A higher correlation leads to a decrease in the expected utility of the inhabitants. As a result, the equilibrium premiums also decreases. This holds only for high values of $\bar{x}$, i.e., for sufficiently high values of capital and/or premium (see Subsection 3.3 for a discussion). As regards the impact of $p$. The problem is more complex. On the one hand, a higher loss probability leads to a decrease in the expected utility of the inhabitants because the likelihood of a ruin is increasing. On the other hand, it leads to a decrease in the reversion utility level $p U(-l)$ because the expected losses without insurance are increasing too. The impact of $p$ on the equilibrium premium is consequently ambiguous.

Proposition 3 also shows the importance of the economic capital $c$. First, it is worth noticing that the capital has a negative impact on the expected profit $(\partial \Pi / \partial c<0)$. The reason is purely mechanical. For a given premium, the insurance company is better off without any capital because the maximum possible loss will be only the total premium $\alpha n$ in case of ruin (see Subsection 3.3 for the implication of this result on the value of the pure premium). However, the capital also has an indirect positive impact on the expected profit: a higher capital per head leads to a decrease in the ruin probability (from Equation 3 ) and consequently to an increase in (1) the utility of the inhabitants $(\partial V / \partial c<0),(2)$ the equilibrium premiums $\left(\partial \alpha^{*} / \partial c>0\right)$ and $(3)$ the expected profit $\left(\partial \Pi / \partial \alpha^{*}>0\right)$.

All theses results, point out that correlated risks should be associated with lower premiums, which is not really in accordance with the usual literature. To understand this result, it should be noticed that for an equivalent individual risk $p$, highly correlated risks means that there is a significant chance for the insurance company to go bankrupt, which is not the case with an infinite number of independent risks. As a consequence, the demand for natural catastrophe insurance contract should be lower with catastrophic risks, which would make the insurance company provide coverage at a more attractive price.

Of course, the properties of the cumulative distribution function $F$ used in the models are important in our analysis. It is consequently important to check the validity of these properties with respect to the recent literature about nonindependence. The next subsection remedies 
this shortcoming and presents a simple technique to model dependency between risks. Last subsection will then investigate the two models of insurance by simulation methods .

\subsection{Probabilities of natural event occurrence}

Various models dealing with nonindependence have recently been proposed in the actuarial literature (see, among others, Bäuerle and Müller, 1998; Albers, 1999; Cossette et al., 2002; Denuit et al., 2005). There are mainly two techniques to incorporate dependence, both using mixture models, i.e., probabilistic models for density estimation using several distributions. The first technique consists in using a discrete common shock model, with a dichotomous variable describing the occurrence of a catastrophe in a given region. The second focuses on a frailty type model, with a continuous variable describing the intensity of the catastrophe in a given region. The present subsection will be interested in the first approach, which allows to derive much more simple results. The distribution function of $N$ (or equivalently $X$ ) will be defined as a mixture model that depends on three probabilities (see for instance Denuit et al., 2005, Chapter 3):

- $p^{*}=\mathbb{P}(\mathrm{Cat}) \in[0 ; 1]$ is the probability of a natural catastrophe, with $1-p^{*}=\mathbb{P}($ No Cat $)$.

- $p_{N} \in[0 ; 1]$ is the probability for an individual to claim a loss in case of no natural catastrophe.

- $p_{C} \in[0 ; 1]$ is the probability for an individual to claim a loss in case of natural catastrophe. We assume that $p_{C} \geq p_{N}$, i.e., a natural catastrophe increases risk occurrence.

The loss probability for an individual is then given by:

$$
p=p_{N}\left(1-p^{*}\right)+p_{C} p^{*}
$$

Conditional to the occurrence or not of a natural catastrophe, risks between individuals are assumed to be independent. For example, if $p^{*}=p_{N}=p_{C}=10 \%$, the loss probability is equal to $p=10 \%$, and the distribution of $N$ is simply given by the binomial distribution $\mathscr{B}(n, 10 \%)$. In contrast, if $p^{*}=10 \%, p_{N}=0 \%$ and $p_{C}=100 \%$, the loss probability is also equal to $p=10 \%$, but the risks are highly correlated since the probability of claiming a loss is 1 in case of a catastrophe (i.e., everybody faces a loss with a probability $p^{*}=10 \%$ ), and 0 otherwise (i.e., nobody faces a loss with a probability $1-p^{*}=90 \%$ ). More generally, given Equation 14, the distribution function of $N$ (and $X$ ) can be defined by the following probabilistic model made of two binomial distributions (for all $k=0 \ldots n$ ):

$$
\begin{aligned}
F(x) & =\mathbb{P}(N \leq k)=\mathbb{P}(N \leq k \mid \text { No Cat }) \times \mathbb{P}(\text { No Cat })+\mathbb{P}(N \leq k \mid \text { Cat }) \times \mathbb{P}(\text { Cat }) \\
& =\sum_{j=0}^{k}\left(\begin{array}{l}
n \\
j
\end{array}\right)\left[\left(p_{N}\right)^{j}\left(1-p_{N}\right)^{n-j}\left(1-p^{*}\right)+\left(p_{C}\right)^{j}\left(1-p_{C}\right)^{n-j} p^{*}\right]
\end{aligned}
$$

where where $k / n \leq x<(k+1) / n$. To simplify, we can set:

$$
p_{C}=\frac{1}{1-\delta} p_{N},
$$


which allows us to write $p_{N}$ and $p_{C}$ as a function of $p^{*}, p$ and $\delta$ (using Equations 14 and 17):

$$
\begin{aligned}
& p_{N}=\frac{(1-\delta) p}{1-\delta+\delta p^{*}} \\
& p_{C}=\frac{p}{1-\delta+\delta p^{*}}
\end{aligned}
$$

The coefficient $\delta \in\left[0, \min \left\{1, \frac{1-p}{1-p^{*}}\right\}\right]$ is determinant in our analysis and can be seen as a proxy for the correlation between the risks:

Proposition 4. The coefficient $\delta$ is an increasing monotonic function of the correlation between the individual risks.

Proof. See Appendix.

Figure 2 provides an illustration of the cumulative distribution function $F$ when $n=500$, $p^{*}=0.1, p=0.3$, and $\delta=0.4$. In that case, the probabilities $p_{N}$ and $p_{C}$ are equal to 0.28 and 0.47 , respectively. When the loss probability $p$ increases from 0.3 to 0.5 (see Figure 3 ), the distribution function translates to the right, with $p_{N}=0.47$ and $p_{C}=0.78$. On the other hand, an increase in $\delta$ from 0.4 to 0.7 implies a reduction of $p_{N}$ to 0.24 and an increase in $p_{C}$ to 0.81 , which means that when $\delta$ is high, either there is a high number of people claiming a loss, or a low number (see Figure 4). For clarity convenience, the analysis is only interested in the right-hand side of the distribution function around $p_{C}: \bar{x}>x^{*}$ where $x^{*}$ is such that $\partial F / \partial \delta<0, \partial^{2} F / \partial \delta^{2}>0$, and $\partial^{2} F / \partial p^{2}>0$.

Figure 5 provides a comparison with Rothschild and Stiglitz (1976). The top-panel of the figure presents the infinite case with correlated risks. The cumulative distribution function $F$ presents a much sharper curve. The insurance company can set the premium so that $\bar{x}$ is between $p_{N}$ and $p_{C}$. In that case, the company has a $10 \%$ likelihood to go bankrupt. The insurance company can also set the premium so that $\bar{x}$ is greater than $p_{C}$, in which case the ruin probability is null. The bottom-panel displays the infinite case with uncorrelated risks. The function $F$ presents only one bend. In that case, the insurance company can set the premium so that $\bar{x}$ is greater than $p=0.30$ which will guarantee a ruin probability equal to zero.

\subsection{Numerical applications and additional results}

Comparing the equilibriums and deriving general theoretical results as regards the impact of the exogenous variables can be quite difficult given the high number of parameters. This is why it can be helpful to focus on numerical examples. To simplify the analysis, the probability of a catastrophe $p^{*}$ will be given and equal to 0.1 , while the loss will be set to $l=1, n$ to 1000 , and the utility function to $U(Y)=-100\left(e^{-2 Y}-1\right)$, with $U(0)=0$. The function $U$ belongs to the CARA class of utility function which leads to a Constant Absolute Risk Aversion according to the Arrow-Pratt measure of relative risk-aversion (see also Doherty and Schlesinger, 1990 and Cummins and Mahul, 2004 for a application of CARA utility function when there is a nonzero probability of default or when the coverage is constrained by an upper bound, respectively). 

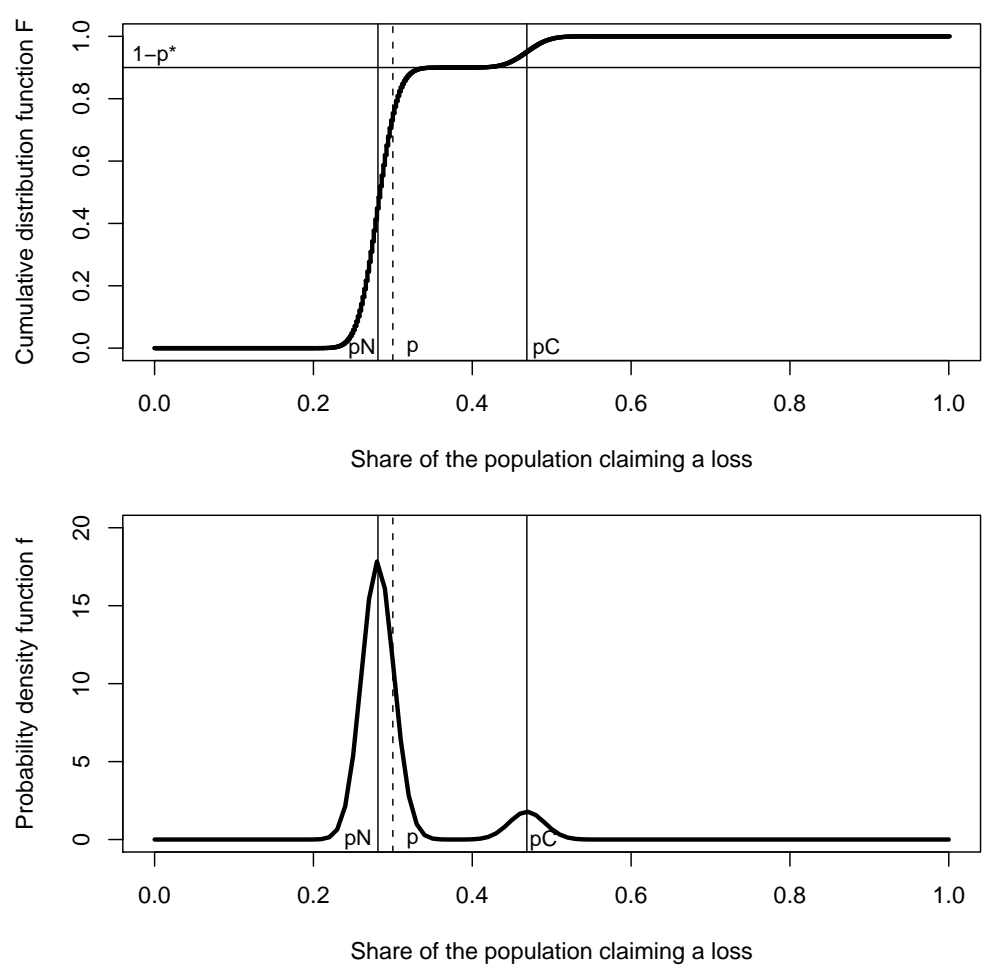

Figure 2. Functions $F$ and $f\left(n=500, p^{*}=0.1, p=0.3, \delta=0.4\right)$
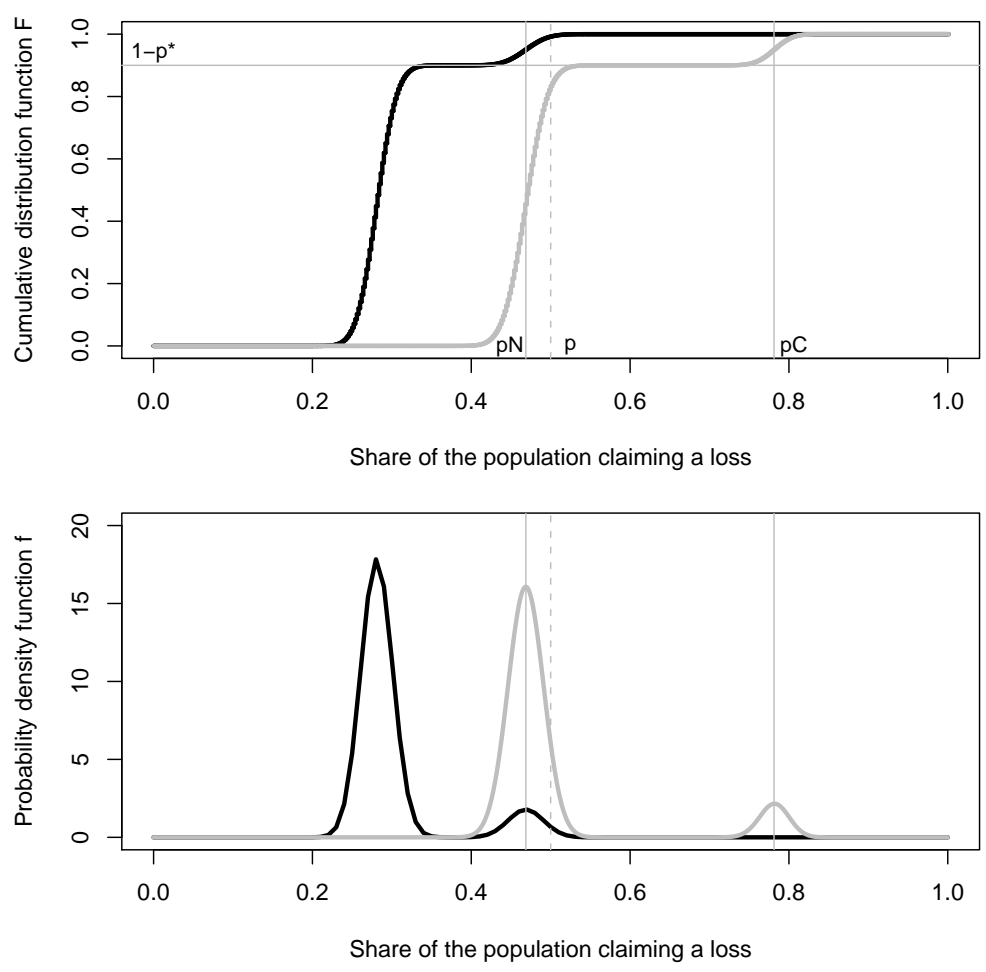

Figure 3. Impact of an increase in $p$ on $F$ and $f(p=0.3$ then 0.5$)$. 

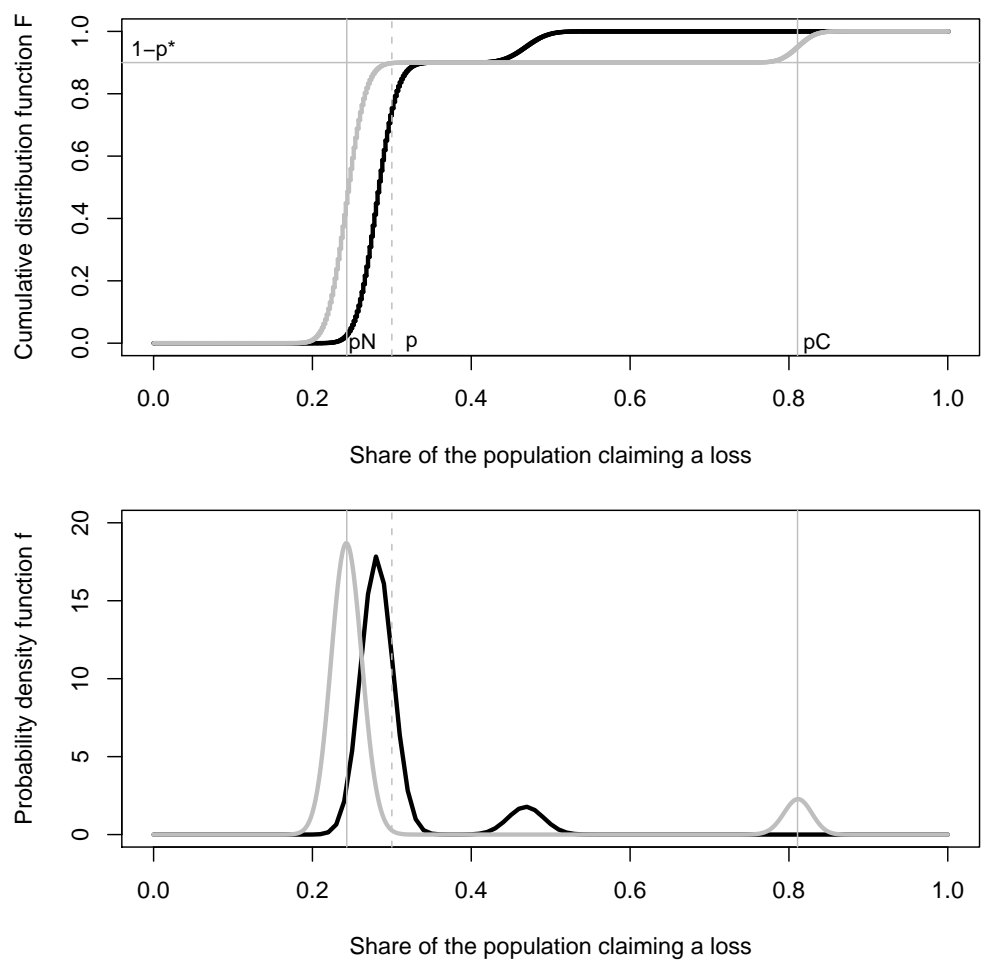

Figure 4. Impact of an increase in $\delta$ on $F$ and $f(\delta=0.4$ then 0.7$)$.
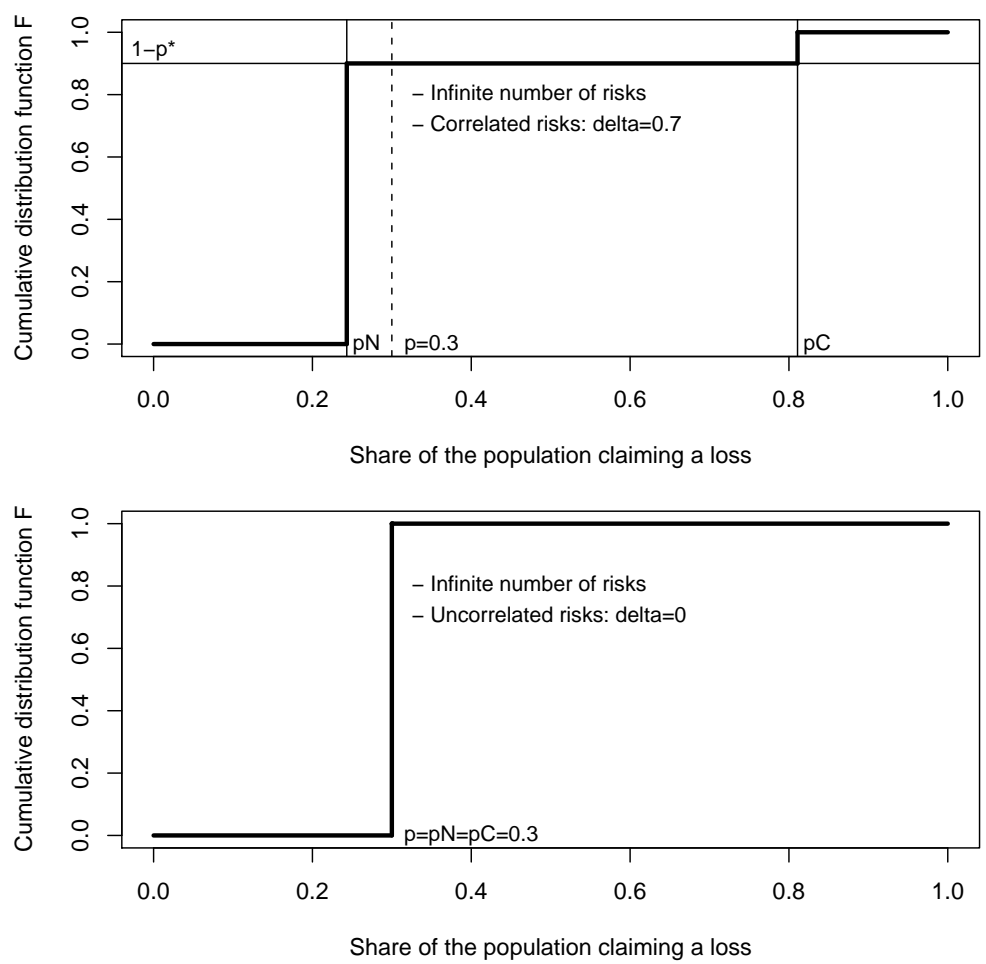

Figure 5. Comparison with Rothschild and Stiglitz (1976) 
Figure 6 presents the expected utility $V$ as a function of the premium $\alpha$ for $c=0.01$, $\delta=0.9$ and $p=0.1$. The grey curve denotes the expected utility without government intervention; the thin black curve represents the case with government intervention and the bold black curve stands for the expected utility received with an infinite number of independent risks, i.e., $U(-\alpha)$. Confirming our expectations, the bold black curve is above the other curves. The two dots on the right stands for the model equilibriums (see Equations 9 and 10). These equilibriums are obtained for the highest possible premiums such that the consumers are indifferent between $V$ and $p U(-l)$. In Figure 6, the equilibrium expected utility is equal to $p U(-l)=-63.9$ in both cases, with $\alpha^{*}=0.238$ without government intervention, and $\alpha^{*}=0.206$ with intervention. The simulations will be implemented from this initial graphic.

Figures 7, 8 and 9 provide an illustration of Proposition 3. In Figure 9, a decrease in the correlation from 0.9 to 0.8 has a positive impact on the expected utility and the equilibrium premiums. The opposite results may actually occur for low values of $\bar{x}$ (see the left-hand side of Figure 9). Indeed, a high correlation between risks means that either there is a high number of people claiming a loss, or a low number. Consequently, for low values of $\bar{x}$, the probability of bankrupt $1-F(\bar{x})$ could decrease with $\delta$ since the chances of having a low population claiming a loss are increasing too. This scenario is however unrealistic since it would imply that the insurance industry will go bankrupt anytime there is a low number of claims.

Figure 8 extends the result of Proposition 3 to an increase in the catastrophe probability $p_{C}$. If $P_{C}$ decreases from 0.526 to 0.2 , the consequence is an increase in $\delta$ from 0.9 to 0.737 (given Equation 17), which implies a higher expected utility for the citizens. In practice, this result highlights the importance of prevention policies in the natural catastrophe insurance industry. Lastly, in Figure 9, an increase in the capital per head from 0.01 to 0.1 has a positive impact on the expected utility and the equilibrium premiums. If $c$ increases, then $\bar{x}$ increases while the ruin probability $1-F(\bar{x})$ decreases, which leads to an increase in the expected utilities. As a consequence, the equilibrium premiums will increase too.

The simulations also offer two other interesting results:

Result 1. Without government intervention, the expected utility function first increases with the premium and then decreases. While surprising at first, this result may be easily explained. Recall that ruin occurs when $X>\bar{x}=(\alpha+c) / l$. If $\alpha$ is small, the probability of a ruin is very high, almost close to 1 , while the indemnity received by the insured is equal to $n c / N$, which is almost close to zero. An increasing premium will increase the indemnity received in case of ruin and will reduce the ruin probability. When this probability becomes insignificant, the expected utility decreases as usual with the premium (see Figure 6).

Result 2. A premium less than the pure premium can lead to a positive expected profit. By definition, the pure premium in the insurance literature is the equilibrium premium for a risk aversion free agent. More specifically, an agent is said to be risk-averse if:

$$
U(-\alpha=-p l)>p U(-l),
$$

i.e., if $U$ is concave (from Jensen inequality). If an agent is willing to accept a premium equal to $p l$, namely the pure premium, then the agent is risk-neutral. Furthermore, in the 


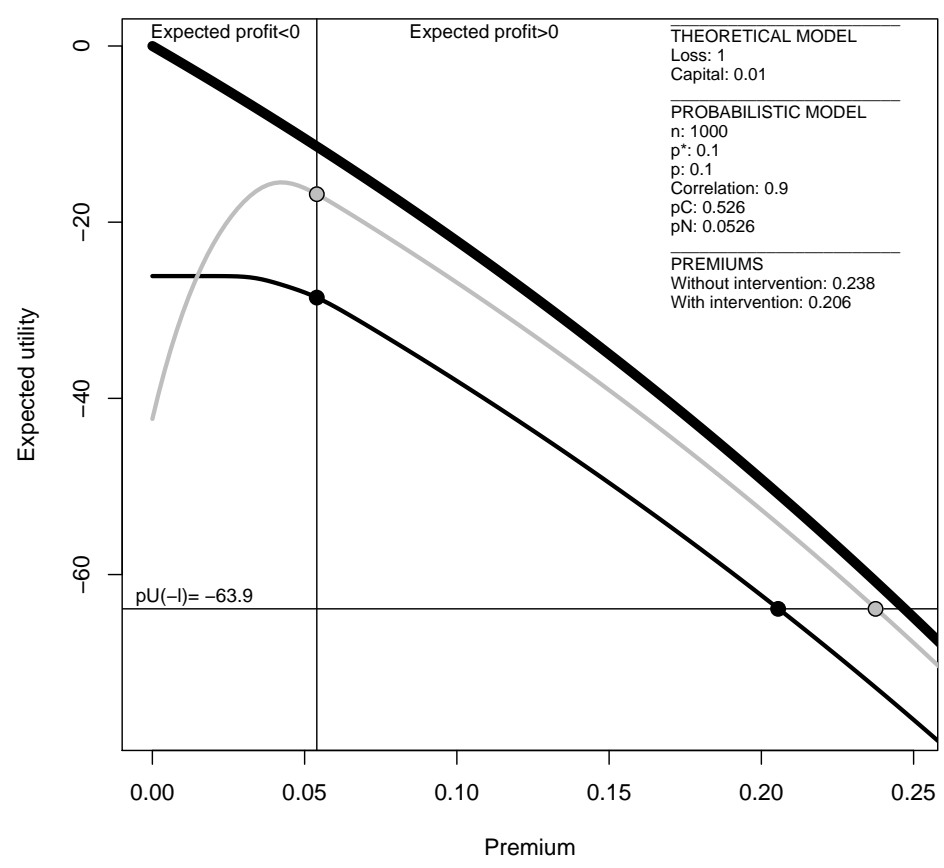

Figure 6. Comparison of equilibriums.

insurance literature, the pure premium is also the premium under which the expected profit of the insurance company is negative. For instance, in Rothschild and Stiglitz (1976), the expected profit for one individual contract is $(1-p) \times \alpha+p \times(\alpha-l)$, which is positive only if $\alpha>p l$, i.e., if $\alpha>p$ when $l=1$. This result does not hold anymore when we introduce the economic capital of the company. Indeed, by definition, the shareholders in a limited company are not personally liable for any of the debts of the company, other than for the value of their investment in that company. Consequently, in case of ruin, the shareholders can lose only $c l$ per individual contract (instead of $l$ ), which leads to a higher expected profit than in the Rothschild and Stiglitz model. Figure 6 provides an illustration of this result. The two dots on the left-hand side of the graphic give the expected utility levels when the expected profit of the insurance company is null. As we can see, the premium that leads to a null expected profit is less than the pure premium $p=0.10$. Consequently, in the two models of natural catastrophe insurance, the outcome may be a premium lower than the usual pure premium, even if the agents still are risk-averse. This result comes from the fact that $\partial \Pi / \partial c<0$ in Proposition 3 .

\section{Policy implication of the models}

This section examines the impact of the individual loss probability, the correlation between the risks and the economic capital on a possible regulation. The first subsection discusses the policy implications of the previous models, when the premium is set by the insurance 


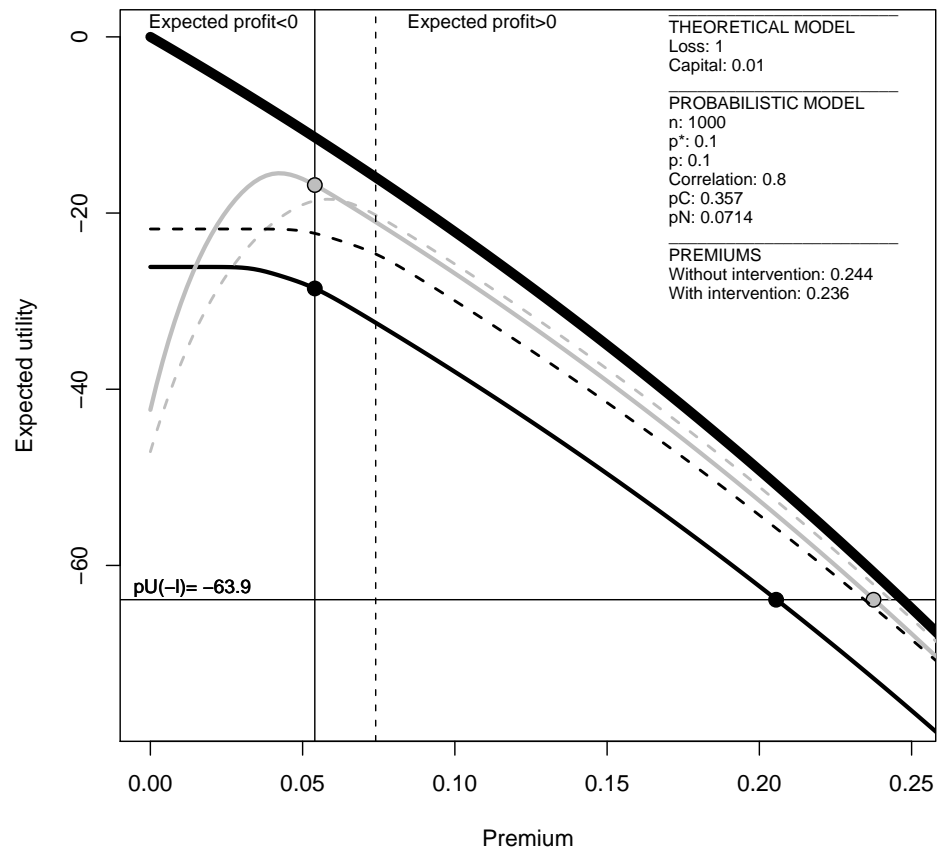

Figure 7. Impact of a decrease in $\delta$ from 0.9 (plain line) to 0.8 (dotted line).

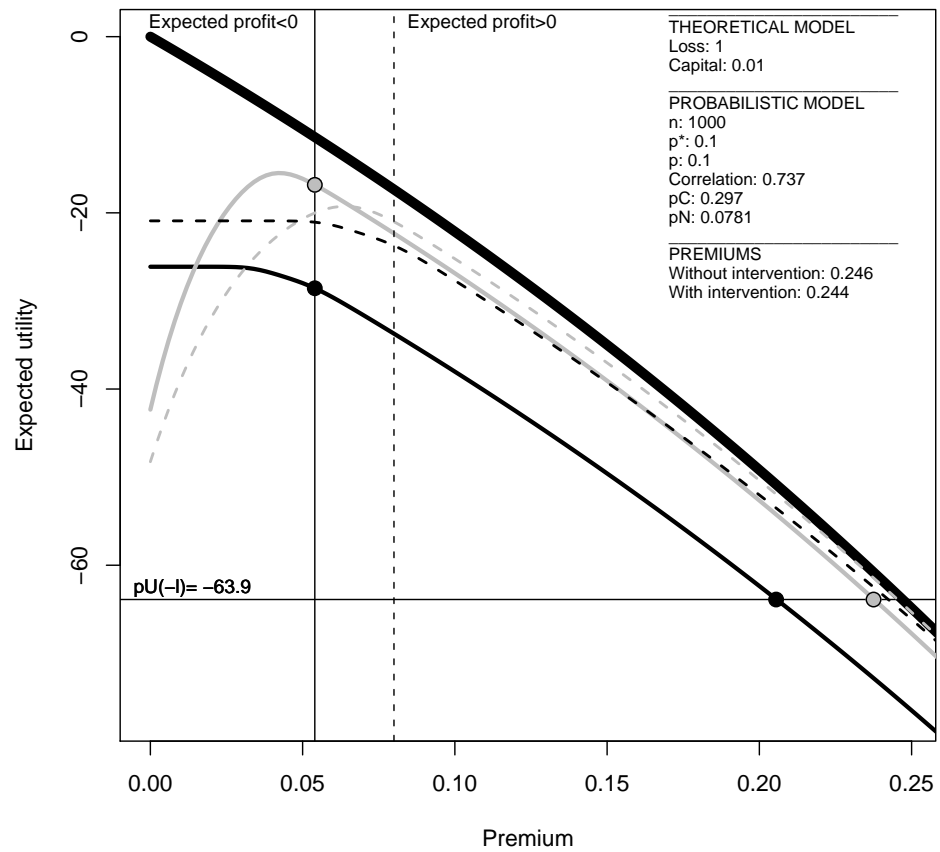

Figure 8. Impact of a decrease in $p_{C}$ from 0.526 (plain line) to 0.2 (dotted line). 


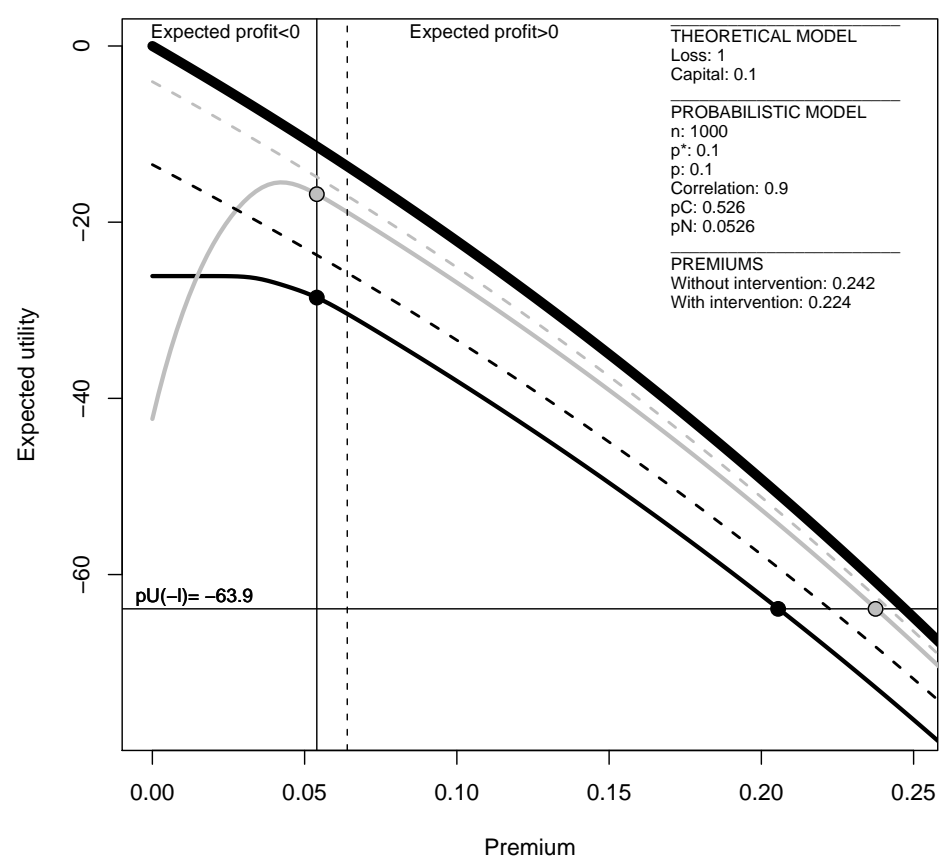

Figure 9. Impact of an increase in c from 0.01 (plain line) to 0.1 (dotted line).

company. The second subsection considers the possibility that the government regulates the premium so as to maximize social welfare.

\subsection{Insurance with non-regulated premiums}

It is worth noticing that whatever the model of natural catastrophe insurance, the equilibrium outcome in terms of expected utility is the same: an individual will reach a utility level equal to $p U(-l)$, which also corresponds to the utility level reached when there is an infinite number of independent risks. The only difference is on the equilibrium levels of the premiums, which according to Proposition 2 are lower if there is a finite number of dependent risks. In other words, if the premiums are set by the monopoly, the debate about government intervention as an insurer of last resort no longer exists in terms of citizens' utility and social welfare. However, the government still needs to solve the considerable information problem inherent to the natural catastrophe insurance industry.

First, the insurance industry relies on predicting and risk-spreading techniques to rate the catastrophe exposures. But the lack of historical data on catastrophic events makes the forecasting of losses difficult. Even worst, developments in ruin theory are recent, and the models dealing with nonindependence have only been proposed recently in the actuarial literature. Given the uncertainty on natural catastrophe occurrence and risks dependency, insurance companies are likely to focus on the worst-case scenario (overestimation of $p$ and $\delta$ ). In that case, the insurance companies could chose not to offer the catastrophe coverage 
if the premium are set at the equilibrium price because the estimated likelihood of a ruin $1-F(\bar{x})$ is too high $(\partial F / \partial \delta<0$ and $\partial F / \partial p<0$ in Equation 2). The following public policy tools, even if they are not a direct implication of our results, worth to be mentioned.

Policy implication 1. The government needs to provide the supply side with a better access to information as regards the occurrence of natural events. This could be done by supporting scientific research in the area in order to improve both the prospective and retrospective analysis of natural disasters. Studies in the field should be able to provide (1) scientific information and theories for the explanation of natural events (i.e., promoting Earth sciences), (2) methods for calculating damages as a result of natural catastrophes and estimating risk perceptions (cost-benefit analysis of natural disasters), (3) a better understanding of people behavior when faced with high-loss/low-probability events (cognitive science and experimental economics) and (4) updated predicting techniques to the insurance companies (mathematics and econometrics).

Second, the way citizens construct their probabilities when faced with high-loss/lowprobability events may be distorted (as for instance in the dual theory of Yaari, 1987 and Kahneman and Tversky's 1979 prospect theory). Examples of such bounded rationality behaviors may be found in Smith and Desvouges (1987), Kunreuther et al. (1988), McClelland et al. (1990), and McClelland et al. (1993) where people are found to have a bimodal value response to low probabilities, i.e., people appear either to dismiss low-probability hazards or to worry to much about them. The consequence is that citizens are likely to refuse the insurance contract in the first case (the loss $p U(-l)$ without insurance is underestimated) or to accept a contract even for a premium charged above the equilibrium premium $(p U(-l)$ is overestimated). In that case, we encourage deeply policy-makers to consider the following policy tools.

Policy implication 2. People may underestimate the likelihood of a natural disaster in which case they could refuse any insurance contracts. They also may worry to much about natural catastrophes and accept a contract even for a premium charged above the reversion equilibrium premium. In the first case, the government could force customers to buy insurance while in the second case, it could regulate the insurance industry by approving or not the premium rates (see Epple and Schäfer, 1996 and Jaffee and Russell, 1997 for practical application of these measures).

Notice that, in our models, the citizens understand that natural risks are correlated and that they are purchasing lower quality coverage than with independent risks. The consequence is that the premiums are set at a lower level too. It should be stressed that this result is not totally in accordance with the usual literature about natural catastrophe insurance. In the existing literature, we find a clear consensus that natural disasters imply higher premiums than independent risks (see for instance Jaffee and Russell, 1997). The present research actually does not deny this result. Given Equation 3, higher premiums reduce the ruin probability 1 $F(\bar{x})$ while, according to Proposition 3, a higher correlation between the individual risks leads to an increase in the ruin probability. Therefore, for a given ruin probability, the impact of a higher correlation can be compensated by an increase in the premium. We actually encourage 


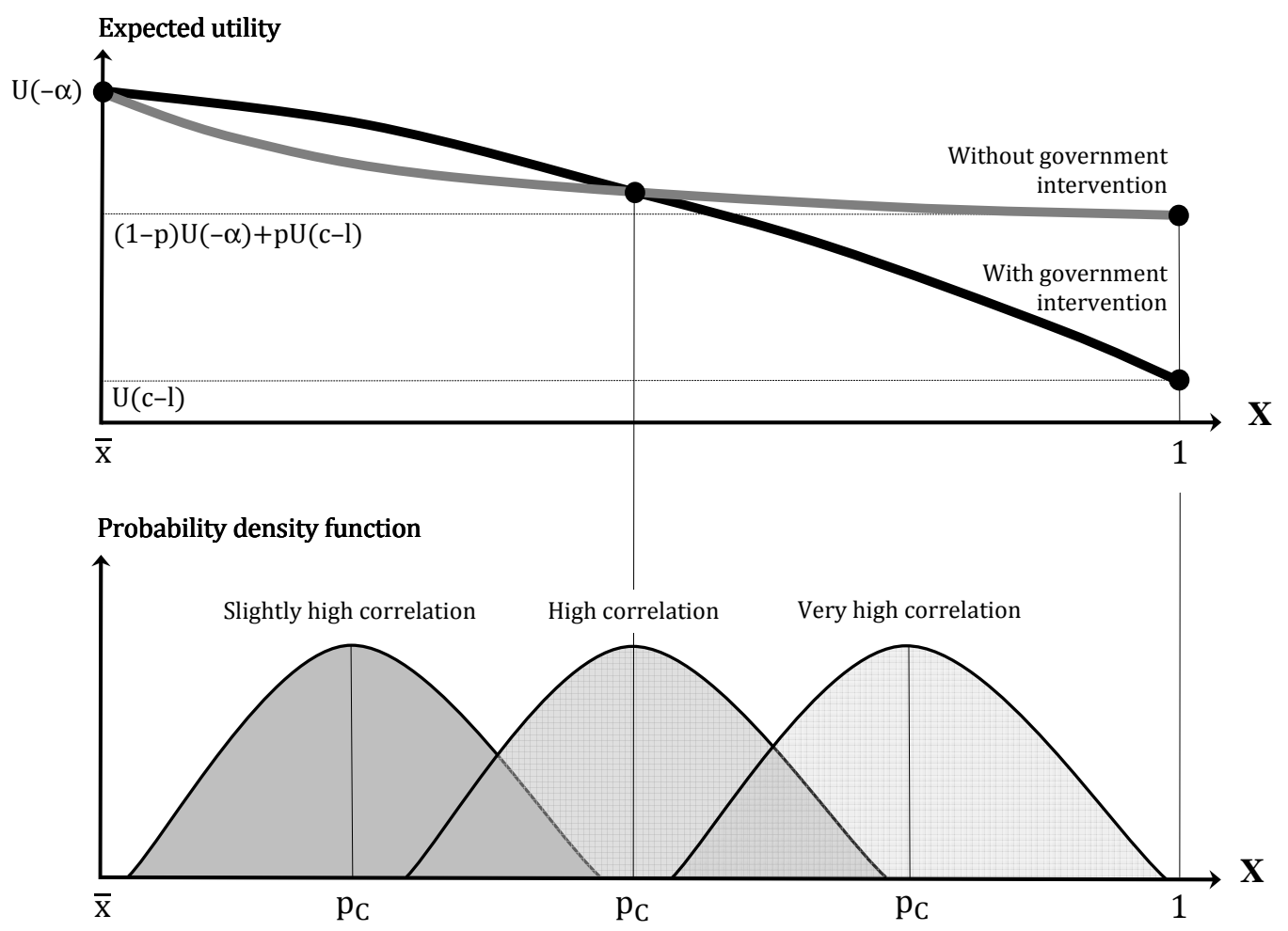

Figure 10. Expected utilities in case of ruin.

future researchers to be more attentive about the objective-function in their models. The purpose of potential purchasers is not to guarantee the solvency of the insurance industry (and to maximize the expected profit of the insurance company), but to maximize their expected utility.

Policy implication 3. Policyholders may not necessarily understand that natural risks are statistically dependent. The consequence would be an underestimated ruin probability and, as a result, an overestimated expected utility and a willingness to pay higher premiums. The government needs to provide the demand side with a better access to information as regards the solvency of insurance companies: without government intervention, there is a slight probability that they receive reduced indemnities; and with government intervention, it is possible that they pay additional premiums or taxes. In other words, the citizens need to understand that risk are correlated and that they are purchasing lower quality coverage than with independent risks. This can be done by supporting agencies that provide financialstrength ratings measuring insurance companies' ability to pay claims (as for instance Standard \& Poor's, A.M. Best Company, Fitch). In the US, several empirical studies have actually found support for demand sensitivity to insurer's financial strength ratings (see for instance Sommer, 1996; Cummins and Danzon, 1997; Epermanis and Harrington, 2006). 


\subsection{Insurance with regulated premiums}

The results that $\partial V / \partial c<0$ and that an increased ruin probability leads to a decrease in the expected utilities confirm the idea that the natural catastrophe insurance industry is characterized by economies of scale. Indeed, large companies should have easier access to capital and could pool the risk with independent risks from other regions (Cummins, 2006; Jafee, 2006). In contrast, since $\partial \Pi / \partial \alpha>0$, small insurance companies might not offer catastrophe coverage because natural risks require too much capital and/or implies non-affordable prices for the consumers (see also Jaffee and Russell, 1997). The presence of large-size private companies is consequently necessary to guarantee the existence of coverage against natural damages (see Epple and Schäfer, 1996 for empirical evidence). The government should consequently encourage the emergence of a monopoly, or at least, not discourage it. In that case, following the usual literature about market inefficiency, the government should be in charge of setting the premium level through some regulation. The Pareto-optimal choice would be the lowest possible premium such that the social welfare, here the expected utility $V$, is maximized subject to the constraint that the industry face at least a positive expected profit (or a ruin probability sufficiently small in the case of a risk-averse company). As regards non-catastrophic losses, empirical evidence of efficient monopolies can be found for instance in Epple and Schäfer (1996), von Ungern-Sternberg (1996) and Felder (1996). These authors show that local state monopolies in Switzerland and Germany propose housing and fire insurance at lower selling prices than do private companies in competitive markets. However, to our knowledge, no study attempts to provide such a comparison in respect to natural catastrophe insurance.

Policy implication 4. The government should encourage the emergence of a monopoly and, as a result, discipline the industry through regulated premiums. This can be done by (1) instituting a strong limit on the companies exposure (minimum capital per head for instance) or (2) implementing a minimum insurance requirement such as a minimum financial strength rating.

In Figure 6, the two dots on the left-hand side of the graphic give the expected utility levels when the expected profit of the insurance company is null. For a premium equal to around 0.05 , the agents will not be in favor of intervention of last resort (thin black curve) because the expected utility obtained in that case is lower. Of course, this is only a particular case. The question that arises now is when one of our two models of natural catastrophe insurance dominates the other in terms of expected utility. From Equations 8 and 13, the expected utility with government intervention is higher than without intervention if and only if:

$$
\int_{\bar{x}}^{1} U(B) f(x) d x \geq(1-p)(1-F(\bar{x})) U(-\alpha)+p \int_{\bar{x}}^{1} U(A) f(x) d x
$$

where $B=\alpha-T(x)=c-x l$ and $A=-\alpha-l+I(x)=-\alpha-l+\frac{c+\alpha}{x}$. The difference between the models comes from the fact that without government intervention (right-hand side of the equation), the citizens still have a chance to pay only $\alpha$ if they do not claim a loss. In contrast, 
with government intervention (left-hand side of the equation), the citizens always have to pay something more in case of ruin, through additional taxes/premiums.

Let denote $\Delta$ the difference between the expected utilities:

$$
\Delta=\int_{\bar{x}}^{1}[U(B)-(1-p) U(-\alpha)-p U(A)] f(x) d x
$$

The quantity $\Delta$ is a function of (1) the difference between $U(B)$ and $(1-p) U(-\alpha)-p U(A)$ and (2) the weights represented by the density function $f(x)$. Figure 10 illustrates the problem. On the top panel of the figure are displayed $U(B)$ in black and $(1-p) U(-\alpha)-p U(A)$ in grey. When $X=\bar{x}$, both utilities are equal to $U(-\alpha)$. In contrast, when $X=1$, we have $U(B)=U(c-l)$ and $(1-p) U(-\alpha)-p U(A)=(1-p) U(-\alpha)-p U(c-l)$. It is also possible to demonstrate that: $\frac{d^{2} U(B)}{d x^{2}}=U^{\prime \prime}(c-x l)<0$ and $\frac{d^{2} U(A)}{d x^{2}}=\frac{2}{x^{3}} U^{\prime}\left(-\alpha-l+\frac{c+\alpha}{x}\right)+$ $\frac{1}{x^{4}} U^{\prime \prime}\left(-\alpha-l+\frac{c+\alpha}{x}\right)>0$. Consequently, the curve is concave with government intervention and convex without intervention, respectively. This result implies that there exists a single intersection point as in Figure 10. As regards the impact of $f$ on $\Delta$, we know that the density function is expected to move to the right when the correlation $\delta$ increases. This is illustrated in the bottom-panel of Figure 10. If the correlation is slightly high, the weights of the density function are on the left (where $U(B)>(1-p) U(-\alpha)+p U(A)$ ), which should lead to a positive value of $\Delta$. On the other hand, if the correlation is very high, the weights of the density function are on the right $(U(B)<(1-p) U(-\alpha)+p U(A))$, which should lead to a negative value of $\Delta$. Figure 7 also provides an illustration of this result. We can see that a decrease in the correlation from $\delta=0.9$ to 0.8 makes the gap between the two curves lower, i.e., favors government intervention. This result may be summarized as follows:

Policy implication 5. Government intervention of last resort is not needed when the correlation between the individual risks is high.

To understand this crucial result, consider a much simpler problem where 10,000 insured face the following lotteries. Assume that ruin always occur in the event of a natural disaster and that $10 \%$ of people are claiming a loss of 100,000 Euros in that case. Consider also that the insurance industry is able to pay compensation for a maximum amount of 5 million Euros. If the government intervenes as an insurer of last resort, it does not matter whether you are claiming a loss or not because everybody is supposed to participate to the insurance system. You will pay $(10,000,000-5,000,000) / 10,000=500$ Euros through additional taxes the years following the catastrophe. On the other hand, without intervention you will get only $5,000,000 / 1000=5000$ Euros in case of a loss, i.e., you will lose a total amount of 95,000 Euros. If the probability of an individual risk is equal to $p=1 \%$, your expected loss in case of a natural catastrophe becomes $0.01 \times 95,000+0.09 \times 0=950$ Euros if you are a risk-neutral agent. You will consequently vote in favor of intervention of last resort. In contrast, assume now that the correlation between the individual risk is much higher than previously and that $50 \%$ of people are now claiming a loss in the event of a natural disaster. With government intervention, you will pay $(50,000,000-5,000,000 / 10,000)=$ 4500 Euros through additional taxes. In contrast, without intervention you will receive 
$5,000,000 / 5000=1000$ in case of a loss, i.e., you will lose a total amount of 99,000 Euros. If the probability of an individual risk is still equal to $p=1 \%$, your expected loss becomes $0.01 \times 99,000+0.09 \times 0=990$ Euros. Consequently, you will be in favor of no intervention since there is still a significant chance to face no loss.

\section{Extension to a two-region economy}

This section extends the previous models by focusing on a simultaneous non-cooperative game combining two regions with heterogeneous within-correlations. More specifically, Subsection 5.1 introduces the new theoretical framework. Subsection 5.2 extends the probabilistic model to the two-region case. Subsection 16 examines the model equilibriums.

\subsection{New theoretical framework}

Consider now an economy with a population living in two different areas, labeled Region 1 and Region 2, with $n_{1}$ and $n_{2}$ inhabitants respectively. Each region is exposed to a natural catastrophe which can cause a loss $l$ to $N_{1}$ inhabitants in Region 1 and $N_{2}$ inhabitants in Region 2. The analysis is interested in the stochastic process $\left(X_{1}, X_{2}\right)$, with $X_{i}=N_{i} / n_{i} \in[0 ; 1]$ for $i=1,2$. The share of total population victim of a disaster is denoted by $X_{0}=N_{0} / n_{0} \in[0 ; 1]$, with $N_{0}=N_{1}+N_{2}$ and $n_{0}=n_{1}+n_{2}$. The natural events are based on the following increasing probability distributions:

$$
\begin{aligned}
& X_{1} \sim F_{1}\left(x_{1} \mid p, \delta_{1}\right)=F_{1}\left(x_{1}\right), \\
& X_{2} \sim F_{2}\left(x_{2} \mid p, \delta_{2}\right)=F_{2}\left(x_{2}\right), \\
& X_{0} \sim F_{0}\left(x_{0} \mid F_{1}, F_{2}, \theta\right)=F_{0}\left(x_{0} \mid p, \delta_{1}, \delta_{2}, \theta\right)=F_{0}\left(x_{0}\right),
\end{aligned}
$$

where $F_{1}$ and $F_{2}$ are assumed to satisfy the properties described in Equation 2. As previously, $p$ represents the probability for an individual to claim a loss. For simplicity, it is assumed that this probability is the same in both regions. In contrast, the correlation between the individual risks in each region (referred to as within-correlation, hereafter), $\delta_{1}$ for Region 1 and $\delta_{2}$ for Region 2, can be different. The function $F_{0}$ is directly derived from $F_{1}$ and $F_{2}$ and depends on how the risks are correlated between the two regions. This between-correlation is denoted by $\theta$. The following assumptions are made as regards $F_{0}$ :

$$
\begin{gathered}
\frac{\partial F_{0}}{\partial p}<0 \forall x \in[0 ; 1], \quad \frac{\partial F_{0}}{\partial \delta_{i}}<0 \forall x>x^{*}, i=1,2 \quad \frac{\partial F_{0}}{\partial \theta}<0 \forall x>x^{*} \\
\frac{\partial^{2} F_{0}}{\partial p^{2}}>0 \forall x>x^{*}, \quad \frac{\partial^{2} F_{0}}{\partial \delta_{i}^{2}}>0 \forall x>x^{*}, i=1,2 \quad \frac{\partial^{2} F_{0}}{\partial \theta^{2}}>0 \forall x>x^{*},
\end{gathered}
$$

Hence, for high values of $x$, greater than $x^{*}$, it is assumed that both the within-correlations and the between-correlation increase the probability for $X_{0}$ to be greater than $x$. In other words the probability that there is a high number of victims in the whole economy increases with $\delta_{1}, \delta_{2}$ and $\theta$. This probability is also assumed to increase at an increasing marginal rate. The 
Table 2. Insurance company solvency and ruin probabilities. ${ }^{a}$

\begin{tabular}{lllll}
\hline \hline Profile & Region 1 & Region 2 & Insurance company solvency & Ruin probability \\
\hline$s=0$ & Insure & Insure & Bankrupt if $n_{1}\left(c+\alpha_{1}\right)+n_{2}\left(c+\alpha_{2}\right)-\left(N_{1}+N_{2}\right) l<0$ & $1-F_{0}\left(\bar{x}_{0}\right)$ \\
$s=1$ & Insure & Don't & Bankrupt if $n_{1}\left(c+\alpha_{1}\right)-N_{1} l<0$ & $1-F_{1}\left(\bar{x}_{1}\right)$ \\
$s=2$ & Don't & Insure & Bankrupt if $n_{2}\left(c+\alpha_{2}\right)-N_{2} l<0$ & $1-F_{2}\left(\bar{x}_{2}\right)$ \\
$s=3$ & Don't & Don't & No insurance industry & 0 \\
\hline \hline
\end{tabular}

${ }^{\mathrm{a}}$ with $\bar{x}_{0}=\frac{n_{1}\left(c+\alpha_{1}\right)+n_{2}\left(c+\alpha_{2}\right)}{\left(n_{1}+n_{2}\right) l}, \bar{x}_{1}=\frac{c+p_{1}}{l}$ and $\bar{x}_{2}=\frac{c+\alpha_{2}}{l}$.

function $F_{0}$ will be useful to understand the impact of pooling the two regions on the ruin probability. Subsection 5.2 will provide an example of such a probability distribution.

For simplicity, it is assumed that there is no mobility between the regions: the natural events are sufficiently rare that people do not change their place of residency so as to reduce their loss probability. Instead, the inhabitants in the two regions have to decide simultaneously whether or not to buy full insurance coverage. There is only one single insurance company in the whole economy. The premiums the inhabitants have to pay can be different and are denoted by $\alpha_{1}$ and $\alpha_{2}$, respectively. The inhabitants in the whole economy are identical, i.e., same utility functions. The citizens only differ in their location and, therefore, in their probability distributions $\left(F_{1}\right.$ or $\left.F_{2}\right)$, which implies by symmetry that the decisions to insure or not will be identical for the individuals of the same region. In other words, it is as if only two players were in play. We will be referring to these players as Region 1 and Region 2. The set of actions available to Regions 1 and 2 is denoted by $\{$ Insure, Don't $\}$. The four possible pure-strategy profiles will be denoted by $s$ with $s=0$ if the inhabitants in Regions 1 and 2 both choose "Insure", $s=1$ if Region 1 chooses "Insure" while Region 2 chooses "Don't", $s=2$ if Region 1 chooses "Don't" while Region 2 chooses "Insure", and $s=3$ if both Regions 1 and 2 choose "Don't".

Without government intervention, the insurance company can go bankrupt if it is not possible anymore to pay the full coverage $l$ to the victims, i.e., if the number of insured people claiming a loss is too high. Table 2 describes the possible cases and provides the related ruin probabilities. The utility function of the inhabitants can be written $U=U\left(Y_{i, s}\right)$ which is here a function of the final loss $Y_{i, s}$ given Region $i$ and the pure-strategy profile $s$. Region $i$ 's payoffs $\left(Y_{i, s}\right)$ are similar to those of Subsection 2.1. The second column of Table 3 provides the values of the indemnity in case of bankrupt. The main difference with the one-region model is that the payoffs $\left(Y_{i, s}\right)$ and the risk that the company goes bankrupt $\left(1-F_{S}\left(x_{s}\right)\right)$ depend now on the number of insured people, and consequently on the strategy profile $(s)$. Consequently, if Region $i$ decides to purchase insurance, its expected utility will depend on $s$ :

$$
\begin{aligned}
V_{i, s}= & U\left(-\alpha_{i}\right)-p \int_{\bar{x}_{s}}^{1}\left[U\left(-\alpha_{i}\right)-U\left(-\alpha_{i}-l+I_{s}(x)\right)\right] f_{s}(x) d x, \\
& \text { for } i=1,2 \text { if } s=0 \text { and } i=s \text { when } s=1,2 .
\end{aligned}
$$

On the other hand, with government intervention, an individual in Region $i$ who buys insurance will always derive a loss equal to $\left(-\alpha_{i}-T_{s}\right)$, where $T_{s}$ denotes the tax collected by 
Table 3. Indemnities and taxes in case of Ruin.

\begin{tabular}{lll}
\hline \hline Profile & Indemnity & Additional tax \\
\hline$s=0$ & $I_{0}\left(X_{0}\right)=\frac{n_{1}\left(c+\alpha_{1}\right)+n_{2}\left(c+\alpha_{2}\right)}{N_{1}+N_{2}}=\frac{n_{1}\left(c+\alpha_{1}\right)+n_{2}\left(c+\alpha_{2}\right)}{\left(n_{1}+n_{2}\right) X_{0}}$ & $T_{0}\left(X_{0}\right)=\frac{\left(N_{1}+N_{2}\right) l-n_{1}\left(c+\alpha_{1}\right)+n_{2}\left(c+\alpha_{2}\right)}{n_{1}+n_{2}}$ \\
$s=1$ & $I_{1}\left(X_{1}\right)=\frac{n_{1}\left(c+\alpha_{1}\right)}{N_{1}}=\frac{c+\alpha_{1}}{X_{1}}$ & $T_{1}\left(X_{1}\right)=\frac{N_{1} l-n_{1}\left(c+\alpha_{1}\right)}{n_{1}}$ \\
$s=2$ & $I_{2}\left(X_{2}\right)=\frac{n_{2}\left(c+\alpha_{2}\right)}{N_{2}}=\frac{c+\alpha_{2}}{X_{2}}$ & $T_{2}\left(X_{2}\right)=\frac{N_{2} l-n_{2}\left(c+\alpha_{2}\right)}{n_{2}}$ \\
\hline \hline
\end{tabular}

Region 2

\begin{tabular}{cccc} 
& & Insure & Don't \\
\cline { 3 - 4 } Region 1 & Insure & $V_{1,0}\left(\alpha_{1}, \alpha_{2}, F_{0}, c\right), V_{2,0}\left(\alpha_{1}, \alpha_{2}, F_{0}, c\right)$ & $V_{1,1}\left(\alpha_{1}, F_{1}, c\right), p_{2} U(-l)$ \\
& Don't & $p_{1} U(-l), V_{2,2}\left(\alpha_{2}, F_{2}, c\right)$ & $p_{1} U(-l), p_{2} U(-l)$ \\
\cline { 3 - 4 } & & &
\end{tabular}

Table 4. Payoffs matrix.

the government on the insured individuals. The third column of Table 3 provides the values of $T_{s}$. The expected utility of an individual is then given by:

$$
\begin{aligned}
V_{i, s}= & U\left(-\alpha_{i}\right)-\int_{\bar{x}_{s}}^{1}\left[U\left(-\alpha_{i}\right)-U\left(-\alpha_{i}-T_{s}(x)\right)\right] f_{s}(x) d x \\
& \text { for } i=1,2 \text { if } s=0 \text { and } i=s \text { if } s=1,2 .
\end{aligned}
$$

For both models (with and without government intervention), the settings may be rewritten in terms of a two-player non-cooperative game whose Nash-Equilibriums give the possible partial equilibriums of demand. The payoffs matrix is presented in Table 4. The first entry in each box is Region 1's expected utility for the corresponding strategy profile; the second is Region 2's. We can see from the payoff matrix that if Region $j$ chooses not to have insurance, then Region $i$ will buy insurance if and only if:

$$
V_{i, i}\left(\alpha_{i}, F_{i}, c\right) \geq p_{i} U(-l)
$$

Here, we are faced with the same condition than for the one-region model (see Equation 9). The decision to insure depends on the premium level $\left(\alpha_{i}\right)$, the cumulative distribution function $\left(F_{i}\right)$ - i.e., the loss probability $(p)$, the correlation between the risks $\left(\delta_{i}\right)$ - and the economic capital per head of the firm $(c)$. In contrast, if Region $j$ chooses to pay insurance coverage, then Region $i$ will buy insurance if and only if:

$$
V_{i, 0}\left(\alpha_{1}, \alpha_{2}, F_{0}, c\right) \geq p_{i} U(-l)
$$

Consequently, when $s=0$, the expected utility depends on both regions' characteristics: the premiums $\left(\alpha_{1}\right)$ and $\left(\alpha_{2}\right)$, the cumulative distribution function $\left(F_{0}\right)-$ i.e., $(p),\left(\delta_{1}\right),\left(\delta_{2}\right)$, and $(\theta)$ - which is not the case when $s=1,2$.

Lastly, the private company is still assumed to be a risk-neutral agent. The expected profit for each possible strategy profile are given in Table 5. It should be stressed here that the proof of Proposition 1 is still valid in the two-region case, i.e, the expected profit of the 
Table 5. Expected profit of the company.

\begin{tabular}{ll}
\hline \hline Profile & Expected profit \\
\hline$s=0$ & $\int_{0}^{x_{0}}\left[n_{1} \alpha_{1}+n_{2} \alpha_{2}-x\left(n_{1}+n_{2}\right) l\right] f(x) d x-\left[1-F_{0}\left(x_{0}\right)\right] C_{0}$ \\
$s=1$ & $\int_{0}^{x_{1}}\left[n_{1} \alpha_{1}-x n_{1} l\right] f(x) d x-\left[1-F_{1}\left(x_{1}\right)\right] C_{1}$ \\
$s=2$ & $\int_{0}^{x_{2}}\left[n_{2} \alpha_{2}-x n_{2} l\right] f(x) d x-\left[1-F_{2}\left(x_{2}\right)\right] C_{2}$ \\
$s=3$ & 0 \\
\hline \hline
\end{tabular}

insurance company is an increasing function of the premiums. Focusing on a monopolistic behavior, the equilibrium is characterized by the highest possible premium such that the conditions in Equations 28 and 29 are satisfied. Let $\alpha_{1}^{*}$ and $\alpha_{2}^{*}$ denote the equilibrium premiums when only one region chooses to insure. In that case, the equilibrium obtained is strictly identical to the solution derived in the one-region case. In addition, let denote $\alpha_{1}^{* *}$ and $\alpha_{2}^{* *}$ the equilibrium premium when both regions choose to insure. In that case, the following proposition can be proven:

Proposition 5. The two models of natural catastrophe insurance lead to the following comparative static derivatives (for $i=1,2$ and $i \neq j$ ):

$$
\begin{array}{llll}
\frac{\partial V_{i, 0}}{\partial \delta_{i}}<0 & \text { and } & \frac{\partial \alpha_{i}^{* *}}{\partial \delta_{i}}<0, \text { for } \bar{x}>x^{*} \\
\frac{\partial V_{i, 0}}{\partial \delta_{j}}<0 & \text { and } & \frac{\partial \alpha_{i}^{* *}}{\partial \delta_{j}}<0, \text { for } \bar{x}>x^{*}, \\
\frac{\partial V_{i, 0}}{\partial \theta}<0 & \text { and } & \frac{\partial \alpha_{i}^{* *}}{\partial \theta}<0, \text { for } \bar{x}>x^{*}
\end{array}
$$

Proof. See Appendix.

Proposition 5 points out the importance of the correlation parameters $\delta_{1}, \delta_{2}$ and $\theta$. As in the one-region case, a higher within-correlation will always lead to a decrease in the expected utility of the inhabitants. As a result, the equilibrium premiums also decreases. A similar result is reached with the between-correlation. The higher the correlation between the two regions, the higher the ruin probability and the lower the expected utility. This result points out the importance of pooling the risks with independent risks from other regions. Subsection 16 will characterize more precisely the Nash equilibriums. The next subsection provides an example of a cumulative distribution function satisfying the properties of Equation 25.

\subsection{Refinement of the probabilistic model}

The purpose of this subsection is to understand how the pooling of the two regions may affect the ruin probability. The only way to derive results here is to work on a refinement of the probabilistic model presented in subsection 3.2. As regards the properties of the distribution function, $F_{1}$ and $F_{2}$ will be derived from mixture models as in Subsection 3.2. To simplify, it 
is assumed that Region 1 and Region 2 face a similar natural catastrophe probabilities, labeled $p^{*}$. The regions differ only in their within-correlation. Consequently, the probabilities $p_{C}$ and $p_{N}$ can be different. The latter will be denoted $P_{C}^{1}, P_{N}^{1}, P_{C}^{2}, P_{N}^{2}$ for Region 1 and Region 2, respectively.

The function $F_{0}$ is directly derived from $F_{1}$ and $F_{2}$. There are four possible cases depending on whether or not the regions are exposed to catastrophe. The probability that both regions are victim of a disaster will be equal to $\theta$ and, as such, will represents the correlation between the two regions. The three other possible probabilities can be derived as a function of $p_{1}^{*}, p_{2}^{*}$ and $\theta$. The possible cases are described in Table 6 . Let denote $p_{C C}=\theta$ the probability that Regions 1 and 2 are both hit by a catastrophe, $p_{C N}=1-p^{*}$ the probability that only Regions 1 is hit by a catastrophe, $p_{N C}=1-p^{*}$ the probability that only Regions 2 is hit by a catastrophe, and $p_{N N}=1-2 p^{*}+\theta$ the probability that regions 1 and 2 are hit by a catastrophe. The probability density function of $X_{0}$ is then defined by:

$$
f_{0}(x)=p_{C C} f_{C C}(x)+p_{C N} f_{C N}(x)+p_{N C} f_{N C}(x)+p_{N N} f_{N N}(x),
$$

with

$$
f_{i j}(x)=\mathscr{B}\left(n_{1}, p_{i}^{1}\right) \star \mathscr{B}\left(n_{2}, p_{i}^{2}\right),
$$

and where $\star$ denotes the convolution operator.

Figure 11 presents an illustration of the problem when the risks between the regions

are perfectly independent, i.e., when $\theta=\left(p^{*}\right)^{2}$. In black are represented the cumulative distribution function $F_{1}$ (top panel of the figure) and the density $f_{1}$ of Region 1 (bottom panel) when $p=0.3, n_{1}=500, \delta_{1}=0.5$. The grey curve displays $F_{0}$ and $f_{0}$ when this region is pooled with an identical region, given that $\theta=\left(p^{*}\right)^{2}$. As in the one-region model, we are interested in what is going on in the vicinity of $p_{C}$. In Figure 11 , we can see that $F_{0}$ is below $F_{1}$ around $p_{C}$. In other words, when $\theta=\left(p^{*}\right)^{2}$, pooling Region 1 with another region decreases the probability that there is a high number of people claiming a loss. In contrast, Figure 12 displays the case when the risks are positively dependent, i.e., when $\theta=p^{*}$. In that case $F_{0}$ is above $F_{1}$ in the vicinity of $p_{C}$. In other words, when $\theta=p^{*}$, pooling Region 1 with another region increases the probability that there is a high number of people claiming a loss.

Figure 13 and 14 consider an asymmetric where one region has a higher correlation than the other. More specifically, in Figure 13, the risk between the regions are independent, i.e., $\theta=\left(p^{*}\right)^{2}$, with $\delta_{1}=0.5$ and $\delta_{2}=0.7$. We can see in that case that $F_{0}$ is below $F_{1}$ around $p_{C}$, which points out that pooling Region 1 with a more correlated area will be detrimental to Region 1. On the other hand, pooling Region 1 with a less correlated area will be beneficial to Region 1 (see Figure 14 where $\delta_{1}=0.5$ and $\delta_{2}=0.3$ ).

\subsection{Nash equilibriums and policy implications}

To simplify the analysis, we will assume in this subsection that the natural events probabilities and the demand characteristics are such that the insurance company will always reach a positive expected profit in each equilibrium, i.e., will always accept to provide insurance to Region 1 only, to Region 2 only or to both Regions.

When both regions choose to insure, the following proposition can be proven: 
Table 6. Catastrophe probabilities in the two-region economy.

\begin{tabular}{lc|c|c|c}
\hline \hline & \multicolumn{2}{c}{ Cat in Region 1 } & \multicolumn{2}{c}{ No Cat in Region 1 } \\
\hline & Cat in Region 2 & No Cat in Region 2 & Cat in Region 2 & No Cat in Region 2 \\
\hline General case & $\theta$ & $p^{*}-\theta$ & $p^{*}-\theta$ & $l-2 p^{*}+\theta$ \\
Perfectly independent & $(p *)^{2}$ & $p^{*}\left(1-p^{*}\right)$ & $p^{*}\left(1-p^{*}\right)$ & $\left(1-p^{*}\right)\left(1-p^{*}\right)$ \\
Positively dependent & $p^{*}$ & 0 & 0 & $1-p^{*}$ \\
\hline \hline
\end{tabular}
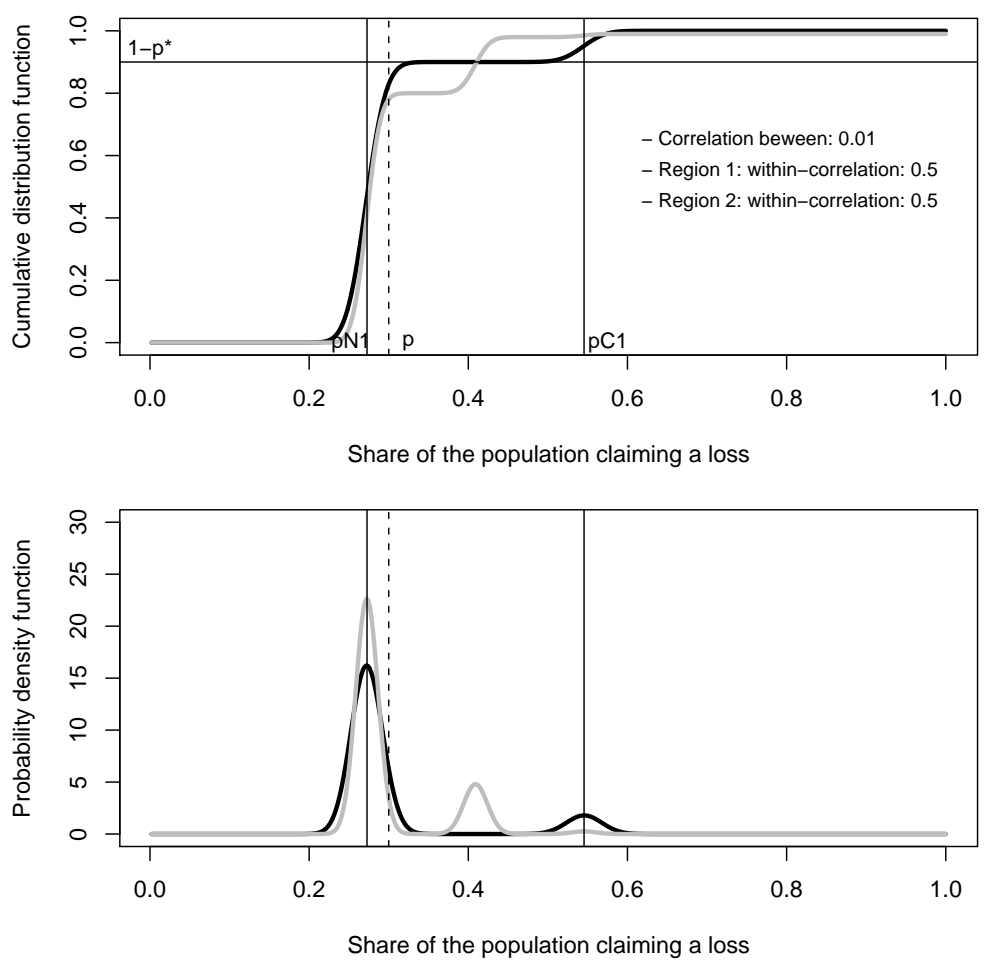

Figure 11. $F_{1}$ and $F_{0}$ when the risks are perfectly independent. 

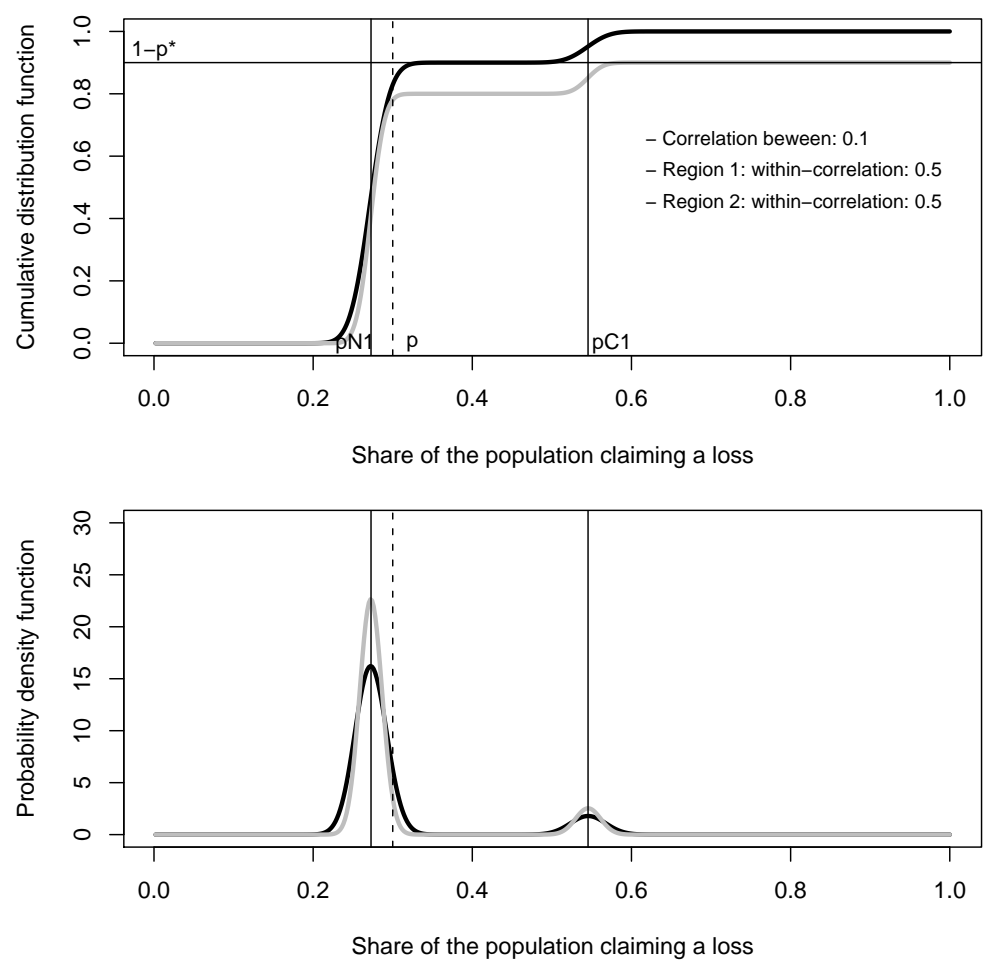

Figure 12. $F_{1}$ and $F_{0}$ when the risks are positively dependent.
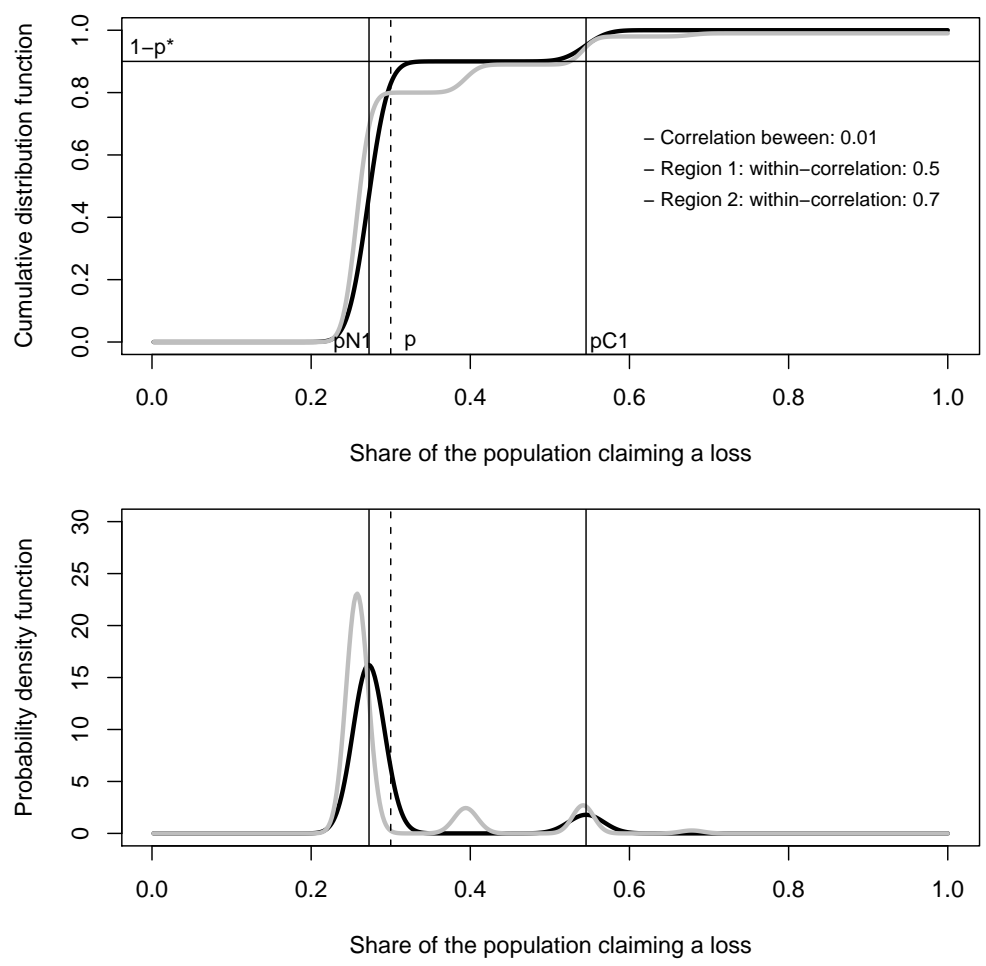

Figure 13. $F_{1}$ and $F_{0}$ when Region 1 has a higher within-correlation. 

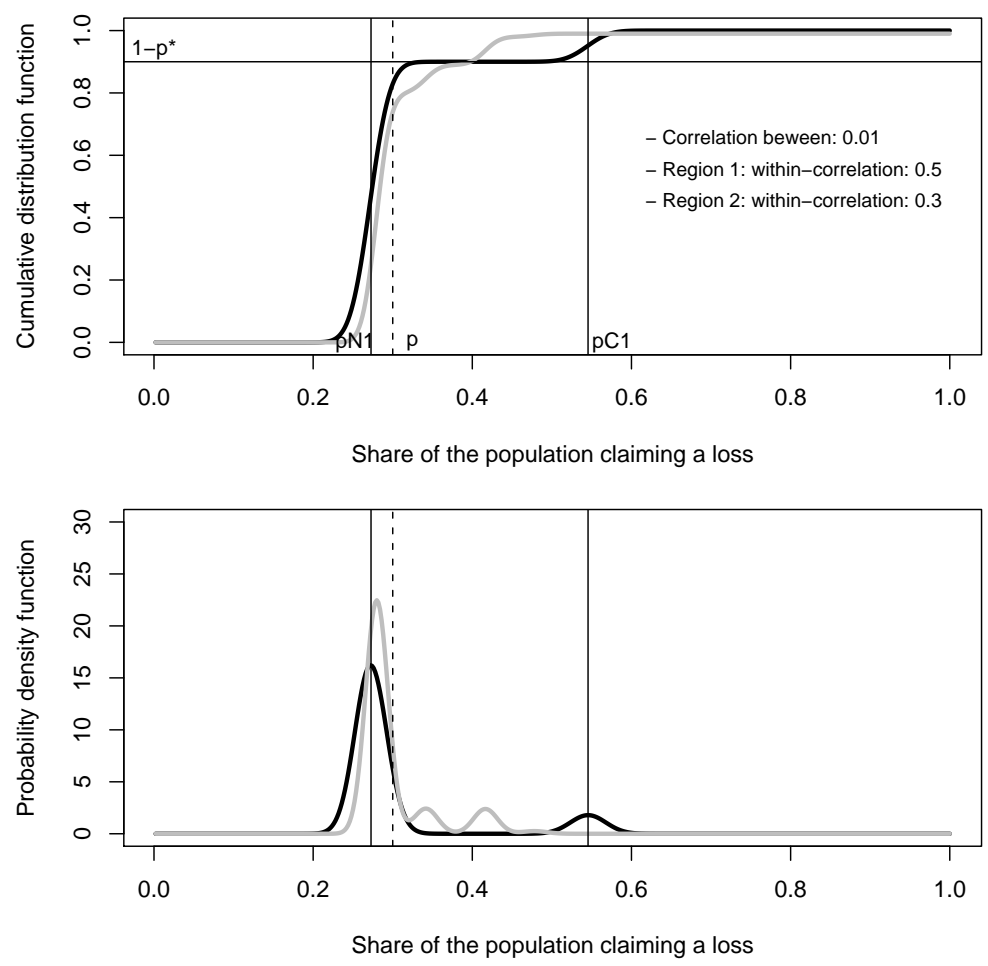

Figure 14. $F_{1}$ and $F_{0}$ when Region 1 has a lower within-correlation.

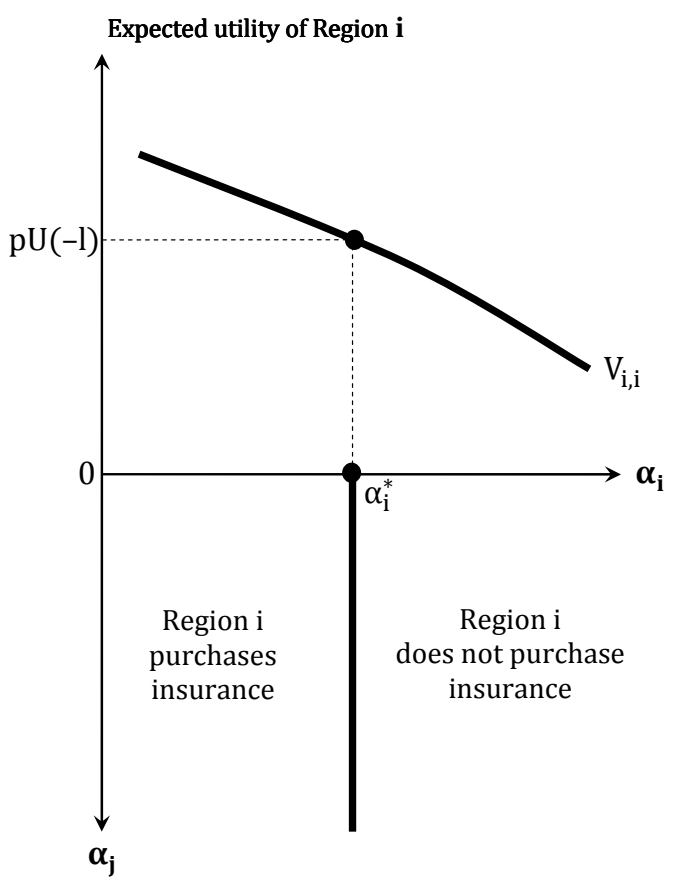

(a) If Region $\mathrm{j}$ chooses not to have insurance

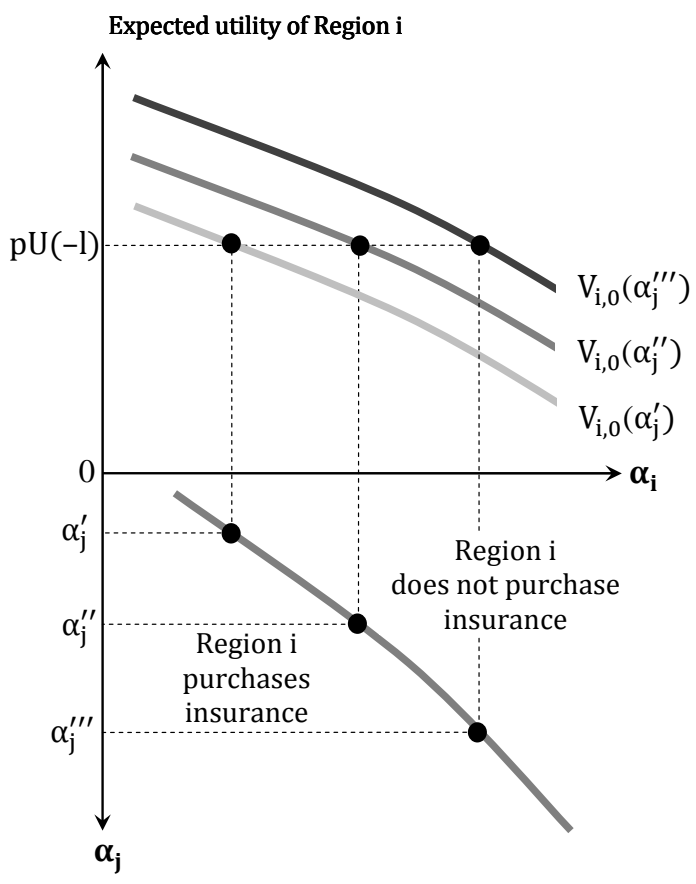

(b) If Region $\mathrm{j}$ chooses to have insurance

Figure 15. Illustration of Equations 28 and 29 
Proposition 6. When both regions decide to purchase insurance, the two-region models of natural catastrophe insurance lead to the following comparative static derivatives:

$$
\frac{\partial V_{i, 0}}{\partial \alpha_{j}}>0, \quad \frac{\partial \alpha_{i}^{* *}}{\partial \alpha_{j}^{* *}}>0, \text { for } i=1,2 \text { and } j \neq i
$$

Proof. See Appendix.

Figure 15 provides an illustration of Proposition 6 and Equations 28 and 29. The left panel displays the case where Region $j$ decides not to purchase insurance. In that case, only the premium $\alpha_{i}$ is determinant in the choice of Region $i$ to insure. In contrast, the right panel displays the case where Region $j$ decides to purchase insurance. The higher the premium of Region $j$, the lower the ruin probability of the insurance company, and the higher the satisfaction of Region $i$. As a result, Region $i$ is willing to pay higher premiums if Region $j$ pays higher premiums too.

The set of Nash equilibriums can be obtained by mixing the left and right panels of Figure 15 together. Figure 16 provides a general illustration of the possible Nash Equilibriums. The black lines represent the cases where only one region is insured $(s=1,2)$. More specifically, over the $a_{2}^{*}$-lines, Region 2 will refuse to purchase insurance, so will Region 1 on the right-hand side of the $a_{1}^{*}$-lines. In other words, the intersection point $(P)$ between the black lines represents the situation where the regions are insured by two different insurance companies for the highest possible premiums. In contrast, the grey curves represent the cases where both regions are insured $(s=0)$. Over the $a_{2}^{* *}$-curves, Region 2 will refuse to purchase insurance, so will Region 1 on the right-hand side of the $a_{1}^{* *}$-curves. The intersection point $(Q)$ between the grey curves consequently represents the situation where both regions are insured by a single insurance company for the highest possible premiums. These curves are increasing with the other region's premium because of Proposition 6. Lastly, the dotted line represents the bisector line where the premiums in Region 1 and Region 2 are identical.

Let us now assume that there exists a value of $\theta \in\left[\left(p^{*}\right)^{2} ; p^{*}\right]$ such that Point $P$ is equal to Point $Q$. This starting situation is represented in Panel $a$ of Figure 16 where the regions are assumed to be stricly identical. Because of this symmetry, the intersection points are on the dotted bisector line and $a_{i}^{* *}(0)$ appears to be lower than $a_{i}^{*}, i=1,2$. According to Proposition 5 , a decrease in $\theta$ will generate an increase in the utilities function $V_{i, 0}$ and the equilibrium premiums $\alpha_{i}^{* *}$. As a result, Point $Q$ will be moving to the North-East of Point $P$. In that case, the regions' willingnesses to pay insurance are higher when the risks are pooled together (see Panel $b$ ). On the other hand, when the between-correlation increases, pooling the risks leads to a decrease in the expected utilities. As a consequence, Point $Q$ will be moving to the South-West of Point $P$. In that case, compared to the one-region case in black, the regions' willingnesses to pay insurance are lower when the risks are pooled together (see Panel $c$ ).

Panel $d$ of Figure 16 also displays the case where Region 1 faces an increase in the within-correlation (i.e., $\delta_{1}$ increases and becomes higher than $\delta_{2}$ ). From Proposition 3 , the intersection Point $P$ will be moving to the West because $\partial V / \partial \delta<0$ and $\partial \alpha^{*} / \partial \delta<0$ in the one-region case. On the other hand, Point $Q$ will be moving to the South-West because both Region 1 and Region 2 will be affected by the increase in $\delta_{1}$ (because $\partial V_{i, 0} / \partial \delta_{i}<0$ 
and $\partial V_{j, 0} / \partial \delta_{i}<0$ in Proposition 5). It should be stressed that when $s=0$, the regions face the same expected utilities. They consequently are willing to accept the same price, which implies that Point $Q$ still is on the bisector line. In that case, the Region 1's willingness to pay insurance is likely to be higher when the risks are pooled together (see also the comments to Figure 13), which is not the case for Region 2. Region 2 will accept to be insured by a single company pooling the risks only if the premium paid is lower than the premium paid when two different companies are providing insurance.

Notice that in our models, in the vicinity of the equilibrium, a higher willingness to pay is synonymous with a higher expected utility (if the premiums remain the same). As consequence, the following policy implications can be highlighted:

Policy implication 6. When the risks between two regions are not sufficiently independent, the pooling of the risks can lead to a Pareto improvement only if the regions have identical within-correlations, ceteris paribus. If the within-correlations are not equal, then the less correlated region needs the premium to decrease to accept the pooling of the risks.

For instance, in Panel $d$ of Figure 16, pooling the risk from the starting Point $P$ without changing the premium levels will have the following consequences. First, Region 1 will accept the pooling since the premium $\alpha_{1}^{*}$ will be lower than the maximum premium $\alpha_{1}^{* *}$ Region 1 would have pay when $s=0$. In that case, we are sure that Region 1 will reach a utility level higher than the reversion utility level $p U(-l)$. On the other hand, Region 2 will not accept the pooling because the premium $\alpha_{2}^{*}$ will be higher than the maximum premium $\alpha_{2}^{* *}$ Region 2 would have pay when $s=0$. In that case, the utility reached by Region 2 is necessarily lower than $p U(-l)$. Hence, Point $P$ cannot be a situation where both regions choose to insure. The only possibility to reach the pooling is by decreasing the premium of Region 2. In contrast, with strictly identical regions (Panel $b$ ), pooling the risk from the starting Point $P$ without changing the premium levels will lead to an increase in both expected utilities since the premiums they will pay $\left(\alpha_{1}^{*}\right.$ and $\left.\alpha_{2}^{*}\right)$ will be lower than the maximum premium $\alpha_{1}^{* *}$ and $\alpha_{2}^{* *}$ they would have pay when $s=0$.

\section{Conclusion}

This research aimed to provide a better understanding of how individuals and private companies behave when covers against natural catastrophes are in play. Following the recent literature on nonindependence and mixture probabilistic models, two main elements are assumed to determinate the occurrence of natural events: first, the probability $(p)$ for each individual to claim a loss, and second, the within-correlation $(\delta)$ between the individual risks. An example of such a probabilistic model is the common shock model that we presented in Section 3.

To sum up the whole story, the within-correlation $(\delta)$ can be said to determinate the severity of natural catastrophes - i.e., the total number of people that will be claiming a loss - which determinates in return the chances for the insurance industry to go bankrupt. The loss probability $(p)$ on the other hand represents the odds for each individual to be one of the victims. Two models of natural catastrophe insurance were analyzed in this context: a model 

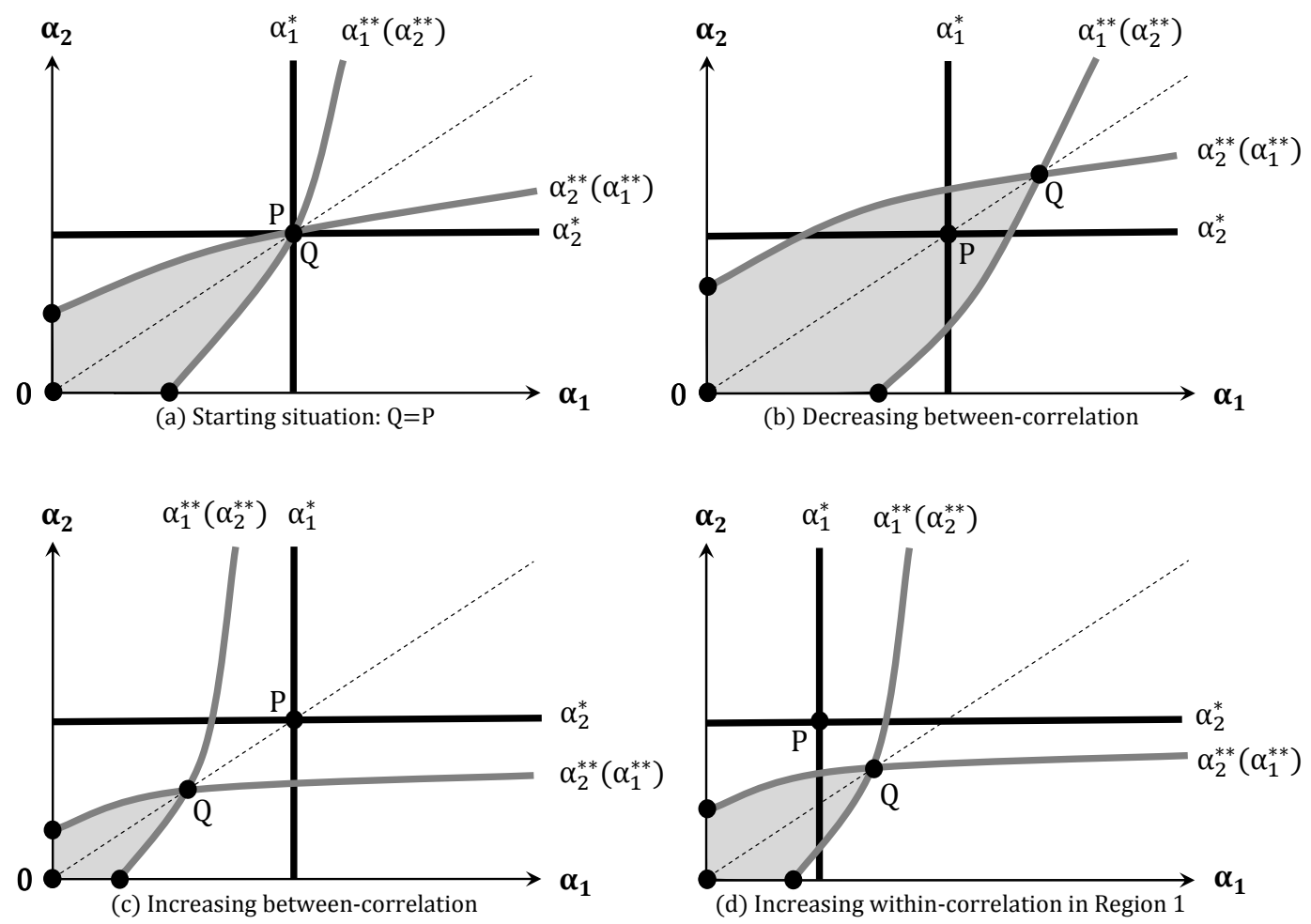

Figure 16. Set of Nash Equilibriums.

of insurance with limited liability and a model with unlimited guarantee. In the first model, the decision to purchase insurance is based on (1) the individual loss probability $(p)$ as in the usual insurance literature, and also (2) the within-correlation $(\delta)$ which determinates the ruin or not of the insurance industry and, consequently, the amount of the indemnities received by each insured claiming a loss. A similar process occurs in the second model except that everybody is asked to participate to the insurance system through additional premiums or higher taxes in case of bankrupt. In addition, the article extends the models by focusing on a simultaneous non-cooperative game combining two regions with heterogeneous within-correlations. In that case, the between-correlation $(\theta)$, i.e., how the risks are correlated between the two regions, also has to be taken into account in the analysis.

The article then discusses the impact of loss probability, correlation and economic capital on a possible regulation. Among several results, the article confirms the idea that the natural catastrophe insurance industry is characterized by economies of scale. The government should consequently encourage the emergence of a monopoly and discipline the industry through regulated premiums. Several reasons are behind this result. First, a large size insurance company should be able to access capital more easily, capital which according to our models will reduce the ruin probability and improve the social welfare. Moreover, the social welfare is maximized when there is an infinite number of independent risks, situation which can be reached only by a large size company that pool the risks with independent risks from other regions. To some extent, this result is empirically supported by Epple and Schäfer (1996), von Ungern-Sternberg (1996) and Felder (1996) who show that local state monopolies 
in Switzerland and Germany provide more efficient housing and fire insurance than do private companies in competitive markets.

The article also points out that government intervention of last resort is not needed when the risks are highly correlated. From the point of view of a potential purchaser, the reason is that the risks of a deficit - and future increases in taxes/premiums - are too important when the risks are highly correlated, while the likelihood of a loss can be very small. In terms of expected utility, an individual is consequently more likely to accept limited liability when faced with severe natural disasters. This is to our opinion the most important finding of this paper. In the absence of empirical work, it may be difficult to provide speculations about the real world. Still, according to the Global Climate Risk Index, the loss due to natural disaster per GDP for the period 1990-2008 were evaluated to $32 \%$ in the US - where insurance for natural catastrophes is available from both private limited liability insurers and public programs - and only 10\% for France, 12\% for Spain and 1\% for Switzerland - where unlimited guarantee has been offered to all private insurers by the government. The fact that limited liability insurance still is available in the US lends support to our finding. Some of the public programs in the US actually led to so large accumulated deficits that homeowners are sometimes encouraged by public officials to purchase insurance from the private market.

Lastly, when the risks between two regions are not sufficiently independent, it is found that the pooling of the risks can lead to a Pareto improvement only if the regions have identical within-correlations. If the within-correlations are not equal, then the less correlated region needs the premium to decrease to accept the pooling of the risks. The two-region model can be a useful normative tool for decision-making in the context of a federal insurance program. A good example is the US National Flood Insurance Program (NFIP), which is under Federal Emergency Management Agency's (FEMA) jurisdiction. This program was created by the Congress of the United States in 1968 through the National Flood Insurance Act of 1968. A characteristic of NFIP is that FEMA sets rates on a nationwide basis, combining and averaging across many geographically diverse areas. For instance, two housing units with the same risk ( $p$ in our models) but located on terrains with different magnitude of damage (related to $\delta$ in our models) - for example, one in a shallow floodplain and the other in a steep and narrow mountain valley - are charged the same rate per $\$ 100$ of insurance coverage (US Government Accountability Office, 2008). According to the two-region model, if this pooling does not significantly reduce the expected losses (for example, the valley and the floodplain are close and $\theta$ is high), such an approach can lead to a Pareto improvement only if the premium paid by the inhabitants of the valley is less than the premium they would have paid without the pooling.

In conclusion, our models try to highlight some key mechanisms in the relationship between insurance companies and potential purchasers when faced with natural disasters. We suspect that the analysis could have implications in other situations as well. The models could be used to analyze general interdependencies in a market, where the failure of a single entity or cluster of entities could cause a cascading failure, which could potentially bankrupt or bring down the entire market. For instance, insurance against terrorism, financial crisis, economic recessions, public provision of fire protection could be subject to an analysis. These and other questions provide a formidable agenda for future research. 


\section{Appendix}

\section{Proof of Proposition 1}

Recall that with a private insurance company,

$$
\Pi(\alpha, p, \delta, c)=\int_{0}^{\bar{x}(\alpha)}[n \alpha-x n l] f(x) d x-[1-F(\bar{x}(\alpha))] c n .
$$

From Leibniz rule,

$$
\frac{\partial \Pi}{\partial \alpha}=\frac{\partial \bar{x}(\alpha)}{\partial \alpha}[n \alpha-\bar{x}(\alpha) n l] f(\bar{x}(\alpha))+\int_{0}^{\bar{x}(\alpha)} n f(x) d x+\frac{\partial F(\bar{x}(\alpha))}{\partial \alpha} c n .
$$

Thus,

$$
\frac{\partial \Pi}{\partial \alpha}=\frac{1}{l}[n \alpha-\bar{x} n l] f(\bar{x})+n F(\bar{x})+\frac{1}{l} f(\bar{x}) c n,
$$

where $\bar{x}=[\alpha+c] / l$. We consequently have:

$$
\frac{\partial \Pi}{\partial \alpha}=n F(\bar{x})>0
$$

The expected profit of the company is consequently an increasing function of $\alpha$. From Equation 3, an increase in alpha results in an increase in $\bar{x}$, and consequently in a decrease in the ruin probability $1-F(\bar{x})$.

\section{Proof of Proposition 2}

Denote $\bar{\alpha}$ the equilibrium premium and $\bar{V}(\alpha)=U(-\alpha)$ the expected utility when there is an infinite number of independent risks, with $\bar{V}$ being continuous and decreasing. There necessarily exists a decreasing inverse function $\bar{V}^{-1}$. Since the expected utility $V$ obtained in our two models is necessarily lower than $U(-\alpha)$ for any value of $\alpha$, we have:

$$
\forall \alpha, \quad \bar{V}(\alpha) \geq V(\alpha) \Leftrightarrow \bar{V}^{-1}(\bar{V}(\alpha)) \leq \bar{V}^{-1}(V(\alpha)) \quad \Leftrightarrow \quad \alpha \leq \bar{V}^{-1}(V(\alpha)) .
$$

From Proposition 1, the insurance company will choose the maximum premium such that people choose to purchase insurance, i.e., $V\left(\alpha^{*}\right)=p u(-l)$ with and without government intervention; and $\bar{V}(\bar{\alpha})=p u(-l)$ with an infinite number of dependent risks. Consequently, for $\alpha=\alpha^{*}$, we have:

$$
\alpha^{*} \leq \bar{V}^{-1}\left(V\left(\alpha^{*}\right)\right) \Leftrightarrow \alpha^{*} \leq \bar{V}^{-1}(p U(-l)) \quad \Leftrightarrow \quad \alpha^{*} \leq \bar{\alpha} .
$$

\section{Proof of Proposition 3}

Without government intervention. The expected utility $V$ is given by:

$$
V(\alpha, p, \delta, c)=U(-\alpha)-p \int_{\bar{x}}^{1}[U(-\alpha)-U(-\alpha-l+I(x))] f(x) d x,
$$

with $I(x)=\frac{c+\alpha}{x}$. The partial derivative with respect to $c$ is:

$$
\frac{\partial V}{\partial c}=-\frac{p}{l}[U(-\alpha)-U(-\alpha-l+I(\bar{x}))] f(\bar{x})+p \int_{\bar{x}}^{1} \frac{U^{\prime}(-\alpha-l+I(\bar{x}))}{X} f(x) d x
$$


i.e., since $I(\bar{x})=l$,

$$
\frac{\partial V}{\partial c}=p \int_{\bar{x}}^{1} \frac{U^{\prime}(-\alpha-l+I(\bar{x}))}{X} f(x) d x>0 .
$$

The partial derivative with respect to $\delta$ is:

$$
\frac{\partial V}{\partial \delta}=-p \int_{\bar{x}}^{1}[U(-\alpha)-U(-\alpha-l+I(x))] \frac{\partial f(x)}{\partial \delta} d x,
$$

which is negative since $\frac{\partial f(x)}{\partial \delta}>0$ for all $\bar{x}>x^{*}$. The partial derivative with respect to $p$ is:

$$
\frac{\partial V}{\partial p}=-\int_{\bar{x}}^{1}[U(-\alpha)-U(-\alpha-l+I(x))] f(x) d x-p \int_{\bar{x}}^{1}[U(-\alpha)-U(-\alpha-l+I(x))] \frac{\partial f(x)}{\partial p} d x,
$$

which is negative since $\frac{\partial f(x)}{\partial p}>0$ for all $\bar{x}>x^{*}$.

With government intervention. The expected utility $V$ is given by:

$$
V(\alpha, p, \delta, c)=U(-\alpha)-\int_{\bar{x}}^{1}[U(-\alpha)-U(-\alpha-T(x))] f(x) d x,
$$

with $T(x)=x l-\alpha-c$. The partial derivative with respect to $c$ is:

$$
\frac{\partial V}{\partial c}=\frac{1}{l}[U(-\alpha)-U(-\alpha-T(\bar{x}))] f(\bar{x}) d x+p \int_{\bar{x}}^{1} U^{\prime}(-\alpha-T(x)) f(x) d x,
$$

i.e., since $T(\bar{x})=0$,

$$
\frac{\partial V}{\partial c}=p \int_{\bar{x}}^{1} U^{\prime}(-\alpha-T(x)) f(x) d x>0 .
$$

The partial derivative with respect to $\delta$ is:

$$
\frac{\partial V}{\partial \delta}=-\int_{\bar{x}}^{1}[U(-\alpha)-U(-\alpha-T(x))] \frac{\partial f(x)}{\partial \delta} d x,
$$

which is negative since $\frac{\partial f(x)}{\partial \delta}>0$ for all $\bar{x}>x^{*}$. The partial derivative with respect to $p$ is:

$$
\frac{\partial V}{\partial p}=-\int_{\bar{x}}^{1}[U(-\alpha)-U(-\alpha-T(x))] \frac{\partial f(x)}{\partial p} d x,
$$

which is negative since $\frac{\partial f(x)}{\partial p}>0$ for all $\bar{x}>x^{*}$.

Equilibrium premiums. Let $V_{1}=V_{1}\left(\delta_{1}, \alpha\right)$ and $V_{2}=V_{2}\left(\delta_{2}, \alpha\right)$ with $\delta_{1} \leq \delta_{2}$. From Proposition 2 we know that $\frac{\partial \Pi}{\partial \alpha}>0$. Let $V_{1}^{-1}$ denote the inverse function of $V_{1}$, with $V_{1}^{-1}=\sup \left\{\alpha \mid V_{1}(\alpha) \geq v\right\}$. It is possible to prove that $V_{1}^{-1}$ is decreasing. Indeed, if $v^{\prime} \leq v^{\prime \prime}$ then we have:

$$
\left\{\alpha \mid V_{1}(\alpha) \geq v^{\prime \prime}\right\} \subset\left\{\alpha \mid V_{1}(\alpha) \geq v^{\prime}\right\} \quad \Rightarrow \quad \sup \left\{\alpha \mid V_{1}(\alpha) \geq v^{\prime \prime}\right\} \leq\left\{\alpha \mid V_{1}(\alpha) \geq v^{\prime}\right\} \quad \Rightarrow \quad V_{1}^{-1}\left(v^{\prime \prime}\right) \leq V_{1}^{-1}\left(v^{\prime}\right) .
$$

From Proposition 2 we know that $V_{1}(\alpha) \geq V_{2}(\alpha)$. Since $V_{1}^{-1}$ is a decreasing function, this is equivalent to:

$$
V_{1}^{-1}\left(V_{1}(\alpha)\right) \leq V_{1}^{-1}\left(V_{2}(\alpha)\right) \Leftrightarrow \alpha \leq V_{1}^{-1}\left(V_{2}(\alpha)\right)
$$


The insurance company will choose the maximum premium such that people choose to purchase insurance, i.e., $V_{1}\left(\alpha_{1}^{*}\right)=p U(-l)$ and $V_{2}\left(\alpha_{2}^{*}\right)=p U(-l)$. Consequently, for $\alpha=\alpha_{2}^{*}$, we have:

$$
\alpha_{2}^{*} \leq V_{1}^{-1}\left(V_{2}\left(\alpha_{2}^{*}\right)\right) \Leftrightarrow \alpha_{2}^{*} \leq V_{1}^{-1}(p U(-l)) \quad \Leftrightarrow \quad \alpha_{2}^{*} \leq \alpha_{1}^{*},
$$

which implies that $\frac{\partial \alpha^{*}}{\partial \delta} \leq 0$. Similarly, since $\frac{\partial V}{\partial c} \geq 0$, we can prove that $\frac{\partial \alpha^{*}}{\partial c} \geq 0$. Lastly, the sign of $\frac{\partial \alpha^{*}}{\partial p}$ cannot be determined because the insurance company will choose the premium such that $V_{1}\left(\alpha_{1}^{*}\right)=p_{1} U(-l)$ and $V_{2}\left(\alpha_{2}^{*}\right)=p_{2} U(-l)$, with $p_{1}>p_{2}$. The quantity $V_{1}^{-1}\left(p_{2} U(-l)\right)$ is consequently unknown.

Insurance company. The expected profit $\Pi$ is given by:

$$
\Pi(\alpha, p, \delta, c)=\int_{0}^{\bar{x}(c)}[n \alpha-x n l] f(x) d x-[1-F(\bar{x}(c))] c n
$$

with $\bar{x}=[\alpha+c] / l$. From Leibniz rule, the partial derivative with respect to $c$ is:

$$
\frac{\partial \Pi}{\partial c}=\frac{\partial \bar{x}(c)}{\partial c}[n \alpha-\bar{x}(c) n l] f(\bar{x}(c))-[1-F(\bar{x}(c))] n+\frac{\partial F(\bar{x}(c))}{\partial c} c n .
$$

Thus,

$$
\frac{\partial \Pi}{\partial c}=\frac{1}{l}[n \alpha-\bar{x} n l] f(\bar{x})-[1-F(\bar{x})] n+\frac{1}{l} f(\bar{x}) c n .
$$

We consequently have:

$$
\frac{\partial \Pi}{\partial c}=-[1-F(\bar{x})] n<0 .
$$

The partial derivative with respect to $\alpha$ has already been proven in Step 1 of Proposition 2 .

\section{Proof of Proposition 4}

Let $Z^{k}$ be the dichotomous variable equal to 1 when individual $k, k=1 . . n$, has a claim. The correlation between risks is given by:

$$
\begin{aligned}
\operatorname{corr}\left(Z^{k}, Z^{l}\right) & =\frac{\operatorname{cov}\left(Z^{k}, Z^{l}\right)}{p(1-p)} \\
& =\frac{\mathbb{P}\left(Z^{k}=1, Z^{l}=1\right)-p^{2}}{p(1-p)} \\
& =\frac{\left(p_{C}\right)^{2} p^{*}+\left(p_{N}\right)^{2}\left(1-p^{*}\right)-p^{2}}{p(1-p)}
\end{aligned}
$$

Replacing $p_{N}$ and $p_{C}$ by Equations 18 and 19 gives the correlation as a function of $\delta$ :

$$
\begin{aligned}
\operatorname{corr}\left(Z^{k}, Z^{l}\right) & =\frac{p}{1-p}\left[\frac{p^{*}+\left(1-p^{*}\right)(1-\delta)}{\left(1-\delta-\delta p^{*}\right)^{2}}-1\right] \\
& =\frac{p}{1-p}[g(\delta)-1]
\end{aligned}
$$

The derivative of $g$ with respect to $\delta$ is given by:

$$
\frac{d g}{d \delta}=2 p^{*} \times \frac{2-\delta+\delta p^{*}}{1-\delta-\delta p^{*}}
$$


The derivative $\frac{d g}{d \delta}$ is positive for $\delta \in[0 ; 1]$, which implies that $\operatorname{corr}\left(X^{k}, X^{l}\right)$ is a positive function of $\delta$. Moreover, if $\delta=0$, then $p_{N}=p_{C}=p$ in Equations 18 and 19. In that case, we have $\mathbb{P}\left(Z^{k}=1, Z^{l}=1\right)=p^{2}$ and $\operatorname{corr}\left(Z^{k}, Z^{l}\right)=0$, which corresponds to the independent case. On the other hand, if $\delta=(1-p) /\left(1-p^{*}\right)$, then $p_{N}=\left(p-p^{*}\right) /\left(1-p^{*}\right)$ and $p_{C}=1$. In that case, we have $\mathbb{P}\left(Z^{k}=1, Z^{l}=1\right)=\left(p^{*}(1-p)^{2}\right) /(1-p *)+p^{2}$ and $\operatorname{corr}\left(Z^{k}, Z^{l}\right)=\left[p^{*}(1-p)\right] /\left[p\left(1-p^{*}\right)\right]$, which corresponds to the perfectly dependent case when $p=p^{*}$, i.e., when $\mathbb{P}\left(Z^{k}=1, Z^{l}=1\right)=p$ and $\operatorname{corr}\left(Z^{k}, Z^{l}\right)=1$. In other words, the lower $\delta$, the closer $p_{N}$ and $p_{C}$ and the more independent the risks.

\section{Proof of Proposition 5}

The proofs are similar to the proof that $\partial V / \partial \delta<0$ and $\partial \alpha^{*} / \partial \delta<0$ in Proposition 3.

\section{Proof of Proposition 6}

For Region 1, an increase in $\alpha_{2}$ is similar to an increase in the economic capital. The proof that $\frac{\partial V_{1,0}}{\partial \alpha_{2}}>0$ is consequently similar to the proof that $\frac{\partial V}{\partial c}>0$ in Proposition 3. As a result, the proof that $\frac{\partial \alpha_{1}^{*} *}{\partial \alpha_{2}^{*} *}>0$ is equivalent to the proof that $\frac{\partial \alpha^{*}}{\partial c}>0$. By symmetry, this result holds for Region 2 . 


\section{References}

Akerlof, G. (1970). The market for "lemons" : Quality uncertainty and the market mechanism. Quarterly Journal of Economics, 84:488-500.

Albers, W. (1999). Stop-loss premiums under dependence. Insurance: Mathematics and Economics, 24:173-185.

Borch, K. L. (1960). The safety loading of reinsurance premiums. Skandinavian Aktuarietidskrift, 43:162-184.

Bäuerle, N. and Müller, A. (1998). Modeling and comparing dependencies in multivariate risk portfolios. ASTIN Bulletin, 98:59-76.

CCR (2007). Les catastrophes naturelles en France, natural disasters in France. CCR Document, April.

Charpentier, A. (2007). Insurability of climate risks. The Geneva Papers on Risk and Insurance Issues and Practice, 33:91-107.

Chiappori, P.-A., Jullien, B., Salanie, B., and Salanie, F. (2006). Asymmetric information in insurance: General testable implications. RAND Journal of Economics, 37:783-798.

Cossette, H., Gaillardetz, P., Marceau, E., and Rioux, J. (2002). On two dependent individual risk models. Insurance: Mathematics and Economics, 30:153-166.

Cummins, J. and Danzon, P. (1997). Price, financial quality, and capital flows in insurance markets. Journal of Financial Intermediation, 6:3-38.

Cummins, J. and Mahul, O. (2004). The demand for insurance with an upper limit on coverage. Journal of Risk \& Insurance, 71:253-264.

Cummins, J. D. (2006). Should the government provide insurance for catastrophes? Federal Reserve Bank of St. Louis Review, 88:337-380.

Cummins, J. D. and Zi, H. (1998). Comparison to frontier efficiency methods: An application to the us life insurance industry. Journal of Productivity Analysis, 10:131-152.

Denuit, M., Dhaene, J., Goovaerts, M., and Kaas, R. (2005). Actuarial Theory for Dependent Risks: Measures, Orders and Models. Wiley.

Doherty, N. and Garven, J. (1986). Price regulation in property-liability insurance: A contingent claims approach. Journal of Finance, 41:1031-1050.

Doherty, N. and Schlesinger, H. (1990). Rational insurance purchasing: consideration of contract nonperformance. Quartely Journal of Economics, 105:245-253.

Einav, L., Finkelstein, A., and Cullen, M. (2010). Estimating welfare in insurance markets using variation in prices. Quarterly Journal of Economics, 125:877-921. 
Emons, W. (2001). Imperfect tests and natural insurance monopolies. Journal of Industrial Economics, 49:247-269.

Epermanis, K. and Harrington, S. (2006). Market discipline in property/casualty insurance: Evidence from premium growth surrounding changes in financial strength ratings. Journal of Money, Credit and Banking, 36:1515-1544.

Epple, K. and Schäfer, R. (1996). The transition from monopoly to competition: The case of housing insurance in baden-wurttemberg. European Economic Review, 40:1123-1131.

Felder, S. (1996). Fire insurance in Germany: A comparison of price-performance between state monopolies and competitive regions. European Economic Review, 40:1133-1141.

Gould, J. (1969). The expected utility hypothesis and the selection of optimal deductibles for a given insurance policy. The Journal of Business, 42:143-151.

Jaffee, D. M. (2006). Commentary on "should the government provide insurance for catastrophes?". Federal Reserve Bank of St. Louis Review, 88:281-285.

Jaffee, D. M. and Russell, T. (1997). Catastrophe insurance, capital markets, and uninsurable risks. Federal Reserve Bank of St. Louis Review, 64:205-230.

Johnson, H. and Stulz, R. (1987). The pricing of options with default risk. Journal of Finance, 42:267-280.

Kahneman, D. and Tversky, A. (1979). Prospect theory: An analysis of decision under risk. Econometrica, 47:263-291.

Kunreuther, H. (1984). Causes of underinsurance against natural disasters. The Geneva Papers on Risk and Insurance, 31:206-220.

Kunreuther, H. R., Desvousges, W. H., and Slovic, P. (1988). Nevada's predicament: Public perceptions of risk from the proposed nuclear waste repository. Environment, 30:16-20,3033.

Magnan, S. (1995). Catastrophe insurance system in france. Geneva Papers on Risk and Insurance-Issues and Practices, 20:474-480.

McClelland, G. H., Schulze, W. D., and Coursey, D. L. (1993). Insurance for low-probability hazards: A bimodal response to unlikely events. Journal of Risk and Uncertainty, 7:95-116.

McClelland, G. H., Schulze, W. D., and Hurd, B. (1990). The effect of risk beliefs on property values: A case study of a hazardous waste site. Risk analysis, 10:485-497.

Moréteau, O. (2007). Policing the compensation of victims of catastrophes: Combining solidarity and self-responsibility. In van Boom, W. H. and Faure, M., editors, Shifts in Compensation Between Private and Public Systems, pages 131-152. 
Mossin, J. (1968). Aspects of rational insurance purchasing. Journal of Political Economy, 76:553-568.

Rothschild, M. and Stiglitz, J. E. (1976). Equilibrium in competitive insurance markets: An essay on the economics of imperfect information. The Quarterly Journal of Economics, 90:630-49.

Schlesinger, H. and v. d. Schulenburg, J. M. G. (1987). Risk aversion and the purchase of risky insurance. Zeitschrift fur Nationalokunomie, 47:309-314.

Smith., V. K. and Desvousges, W. H. (1987). An empirical analysis of the economic value of risk changes. Journal of Political Economy, 95:89-114.

Smith, V. L. (1968). Optimal insurance coverage. Journal of Political Economy, 76:68-77.

Sommer, D. (1996). The impact of firm risk on property-liability insurance prices. Journal of Risk and Insurance, 63:501-514.

Sonnenholzner, M. and Wambach, A. (2004). Oligopoly in insurance markets. In Wiley, J. and Sons, editors, Encyclopedia of Actuarial Science, pages 131-152. New Jersey.

Tapiero, C., Kahane, Y., and Jacque, L. (1986). Insurance premiums and default risk in mutual insurance. Scandinavian Actuarial Journal, pages 82-97.

US Govenment Accountability Office (2005). Catastrophe risk: U.S. and European approaches to insure natural catastrophe and terrorism risks. Report to the Chairman, Committee on Financial Services, House of Representatives.

US Govenment Accountability Office (2008). Flood insurance: Fema's rate-setting process warrants attention. Report to the Ranking Member, Committee on Banking, Housing, and Urban Affairs, U.S. Senate.

von Ungern-Sternberg, T. (1996). The limits of competition: Housing insurance in Switzerland. European Economic Review, 40:1111-1121.

von Ungern-Sternberg, T. (2004). Efficient Monopolies: The Limits of Competition in the European Property Insurance Market. Oxford University Press, USA.

Wang, K., Huang, R., and Tzeng, L. (2009). Empirical evidence for advantageous selection in the commercial fire insurance market. The Geneva Risk and Insurance Review, 34:1-19.

Yaari, M. E. (1987). The dual theory of choice under risk. Econometrica, 55:95-115. 